OAK RIDGE

NATIONAL LABORATORY

MANAGED BY UT-BATTELLE

FOR THE DEPARTMENT OF ENERGY
ORNL/TM-2000/279

\section{Investigating the Mechanism of Catalytic Tetraphenylborate Decomposition Using Nuclear Magnetic Resonance Spectrometry: Initial Studies in FYOO}

Peter V. Bonnesen

Lætitia H. Delmau

Frederick V. Sloop, Jr. 
ORNL/TM-2000/279

\title{
INVESTIGATING THE MECHANISM OF CATALYTIC TETRAPHENYLBORATE DECOMPOSITION USING NUCLEAR MAGNETIC RESONANCE SPECTROMETRY: INITIAL STUDIES IN FYO0
}

Peter V. Bonnesen, Lætitia H. Delmau, and Frederick V. Sloop, Jr.

\begin{abstract}
The submitted manuscript has been authored by a contractor of the U.S. Government under contract DEAC05-00OR22725. Accordingly, the U.S. Government retains a nonexclusive, royalty-free license to publish or reproduce the published form of this contribution, or allow others to do so, for U.S. Government purposes."
\end{abstract}

Date Published: December 2000

\author{
Prepared by \\ OAK RIDGE NATIONAL LABORATORY \\ Oak Ridge, Tennessee 37831-6285 \\ managed by \\ UT-Battelle, LLC \\ for the \\ U.S. DEPARTMENT OF ENERGY \\ under contract AC05-00OR22725
}




\section{CONTENTS}

Page

LIST OF FIGURES ..v

LIST OF TABLES. vii

ACKNOWLEDGMENTS ix

ACRONYMS AND ABBREVIATIONS xi

EXECUTIVE SUMMARY xiii

1. PROJECT OBJECTIVE. 1

2. TETRAPHENYLBORATE DEGRADATION ...................................

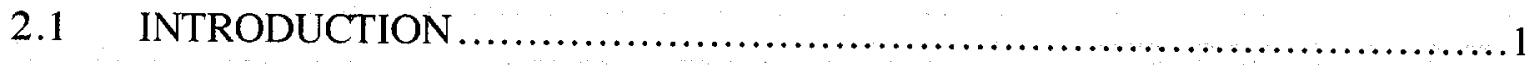

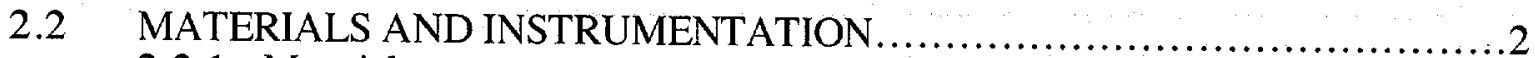

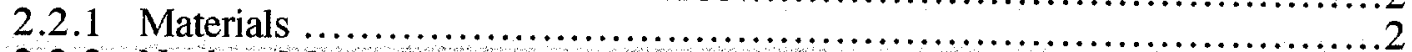

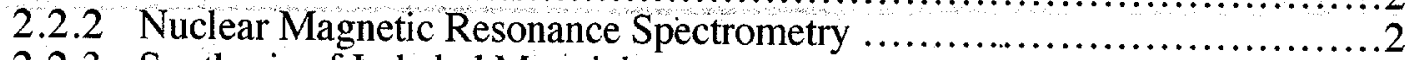

2.2.3 Synthesis of Labeled Materials 3

2.3 TETRAPHENYLBORATE DEGRADATION USING PALLADIUM ON ALUMINA WITH DIPHENYLMERCURY

2.3.1 Introduction..... . .9

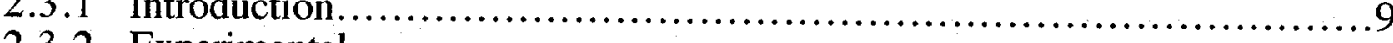

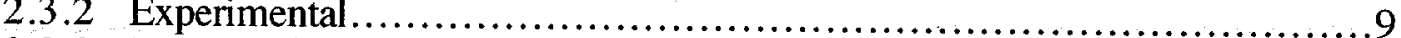

2.3.3 Results and Discussion......................................................... 12

2.4 TETRAPHENYLBORATE DEGRADATION USING PALLADIUM NITRATE AND VARIOUS MERCURY COMPOUNDS …..................... 15

2.4 .1 Introduction................................................................. 15

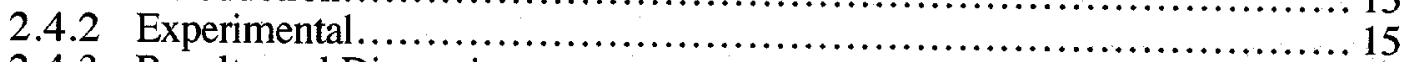

2.4.3 Results and Discussion................................................ 17

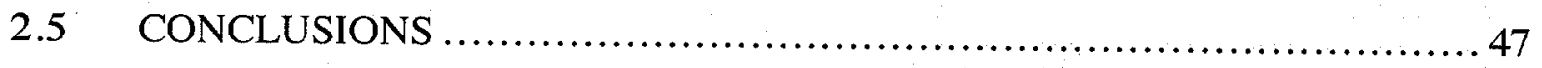

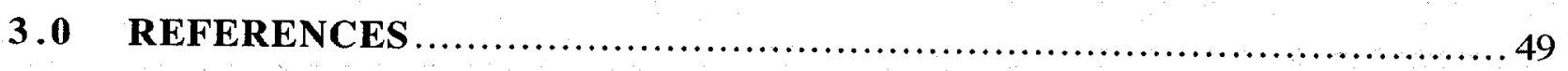




\section{LIST OF FIGURES}

\section{Figure}

1 Comparison of TPB degradation for baseline catalyst case for data obtained by NMR with data previously obtained at SRS.

Distribution of phenylborates as a function of time at $45^{\circ} \mathrm{C}$ and catalyst type.

3 Rate of decomposition of TPB for five-catalyst experiment; baseline reactions from Figure 1 included for comparison.

4 Distribution of phenylborates with time for Reaction \#1 (palladium nitrate only).....

Distribution of phenylborates with time for Reaction \#2 (palladium nitrate plus mercuric nitrate).

6 Distribution of phenylborates with time for Reaction \#3 (palladium nitrate plus $\mathrm{PhHgNO}_{3} \cdot \mathrm{PhHgOH}$ )

$7 \quad$ Distribution of phenylborates with time for Reaction \#4 (palladium nitrate plus diphenylmercury).

8 Appearance of all five reaction bottles after 310 hours and storage in a refrigerator.

9 Appearance of bottle from Reaction \#1 (palladium nitrate only) after 310 Hours and Storage in a Refrigerator.

10 Appearance of bottle from Reaction \#2 (palladium nitrate plus mercuric nitrate) after 310 hours and storage in a refrigerator.

11 Appearance of bottle from Reaction \#3 (palladium nitrate plus $\mathrm{PhHgNO}_{3} \cdot \mathrm{PhHgOH}$ ) after 310 hours and storage in a refrigerator.

12 Appearance of bottle from Reaction \#4 (palladium nitrate plus diphenylmercury) after 310 hours and storage in a refrigerator.

13 Appearance of bottle from Reaction \#5 $\left(\mathrm{PhHgNO}_{3} \cdot \mathrm{PhHgOH}\right.$ only) after $\mathbf{3 1 0}$ hours and storage in a refrigerator. 


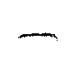




\section{LIST OF TABLES}

Table

Page

1 TPB Degradation NMR Data for Baseline System

12

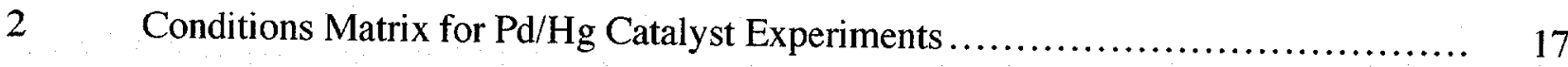

3 TPB Degradation NMR Data for Pd/Hg Catalyst Systems. ...................... 18 


\section{ACKNOWLEDGMENTS}

The authors wish to thank Tim Kent and Joe Walker of the ORNL Chemical Technology Division (CTD) for many helpful discussions, and for their leadership and guidance. Also acknowledged are many colleagues at the Savannah River Site for their generous support, helpful discussions, and guidance, with special thanks extended to Mark Barnes, Reid Peterson, Sam Fink, and Walter Tamosaitis. Also acknowledged are the many good suggestions made by Professor James Boncella (University of Florida), and Professor R. Bruce King (University of Georgia). Finally, the authors wish to thank Jeffrey C. Bryan of the Chemical and Analytical Sdcineces Division for division review of the manuscript.

The authors would like to acknowledge funding from the Tanks Focus Area of EM-50, Office of Science and Technology, Office of Environmental Management, U. S. Department of Energy. 


$$
-
$$




\section{ACRONYMS AND ABBREVIATIONS}

OPB

tetrahydroxyborate, $\mathrm{B}(\mathrm{OH})_{4}{ }^{-}$

$1 \mathrm{~PB}$

phenylboronic acid, $\mathrm{PhB}(\mathrm{OH})_{3}{ }^{-}$

2PB

3PB

diphenylborinic acid, $\mathrm{Ph}_{2} \mathrm{~B}(\mathrm{OH})_{2}{ }^{-}$

triphenylborane, hydroxide adduct, $\mathrm{Ph}_{3} \mathrm{~B}(\mathrm{OH})^{-}$

DOE

Department of Energy

FW

formula weight

ITP

in-tank-precipitation

Lower phenyl borates

$1 \mathrm{~Pb}, 2 \mathrm{~PB}, 3 \mathrm{~PB}$

$\mathrm{M} \Omega$

NMR

mega Ohm

Nuclear Magnetic Resonance

PTFE

SRS

Teflon ${ }^{\circledR}$ FEP

Polytetrafluoroethylene ("Teflon ${ }^{())}$

Savannah River Site

Teflon Fluorinated Ethylene Propylene

Teflon ${ }^{\circledR}$ PFA

Teflon PerFluoroAlkoxy

TPB

tetraphenylborate

WSRC

Westinghouse Savannah River Company 


\section{EXECUTIVE SUMMARY}

At the U.S. Department of Energy's Savannah River Site (SRS), the In-Tank Precipitation (ITP) process uses sodium tetraphenylborate (TPB) to decontaminate soluble High Level Waste (HLW) by precipitating radioactive cesium-137. However, palladium, and possibly other metals that are present in HLW stored at the SRS, are suspected of catalyzing the degradation of the TPB. Testing demonstrated that the present system configuration could not cost-effectively meet the safety and production requirements in the presence of the decomposition reaction. A more fundamental understanding of the mechanism of catalytic degradation of TPB is required to provide a sound technical basis for the Small Tank TPB Precipitation Process proposed as an alternative to ITP. The work described herein was undertaken under Technical Task Plan (TTP) ORNL/CF99/71, entitled "Technical Task Plan for Investigating the Mechanism of Catalytic Tetraphenylborate Decomposition Using Nuclear Magnetic Resonance Spectrometry". The objective of this project was to use, to the extent possible, Nuclear Magnetic Resonance (NMR) spectrometry as an analytical method to gain more insight into the kinetics and degradation mechanism of TPB.

TPB degradation under a variety of catalytic conditions was studied using Boron-10 NMR spectrometry. Both the disappearance of TPB and the ingrowth of the lower phenylborates (1PB, $2 \mathrm{~PB}$, and $3 \mathrm{~PB}$ ) could be observed in the Boron-10 NMR spectra. In one set of experiments, TPB in $2 \mathrm{M} \mathrm{NaOH}$ was heated at $45^{\circ} \mathrm{C}$ using five different catalysts systems (using each metal at one mol\% of TPB concentration): palladium nitrate only; palladium nitrate plus mercuric nitrate; palladium nitrate plus phenylmercuric nitrate basic $\left(\mathrm{PhHgNO}_{3} \bullet \mathrm{PhHgOH}\right) ;$ palladium nitrate plus diphenylmercury $\left(\mathrm{Ph}_{2} \mathrm{Hg}\right)$; and $\mathrm{PhHgNO}_{3} \bullet \mathrm{PhHgOH}$ alone (no palladium). The key findings from this study can be summarized as follows: 1) palladium appears to be capable of catalyzing the degradation in the absence of mercury; 2) when mercury was added to the palladium system in the form of mercuric nitrate or phenylmercuric nitrate basic, the rate of TPB degradation was roughly the same as the rate without mercury present; 3) when mercury was added to the system in the form of diphenylmercury, the rate of TPB degradation was greatly accelerated; 4) no TPB degradation was observed for a system which contained phenylmercuric nitrate basic alone with no palladium present; 5) the distribution of lower phenylborates (1PB, 2PB, and 3PB) varied as a function of the catalyst system; 6) no lower phenylborates were observed to have grown in during the first 17 hours of reaction indicating that an "induction period" may be necessary; and 7) the appearance of the metal precipitates in the reaction mixturc varied with the catalyst system, possibly indicating that the active catalyst that is formed may vary with the chemical form of mercury added. 
$-$ 


\section{PROJECT OBJECTIVE}

At the U.S. Department of Energy's Savannah River Site (SRS), the In-Tank Precipitation (ITP) process uses sodium tetraphenylborate (TPB) to decontaminate soluble High Level Waste (HLW) by precipitating radioactive cesium-137 [1]. However, palladium, and possibly other metals that are present in HLW stored at the SRS, are suspected of catalyzing the degradation of the TPB [2]. Testing demonstrated that the present system configuration could not cost-effectively meet the safety and production requirements in the presence of the decomposition reaction. A more fundamental understanding of the mechanism of catalytic degradation of TPB is required to provide a sound technical basis for the Small Tank TPB Precipitation Process proposed as an alternative to ITP. The work described herein was undertaken under Technical Task Plan (TTP) ORNL/CF99/71, entitled "Technical Task Plan for Investigating the Mechanism of Catalytic Tetraphenylborate Decomposition Using Nuclear Magnetic Resonance Spectrometry". The objective of this project was to use, to the extent possible, Nuclear Magnetic Resonance (NMR) spectrometry as an analytical method to gain more insight into the kinetics and degradation mechanism of TPB.

\section{TETRAPHENYLBORATE DEGRADATION}

\subsection{INTRODUCTION}

This project was, to a large extent, an exploratory project aimed at determining in what manner NMR could be used to learn more about the mechanism of catalytic TPB degradation. Various NMR techniques were considered, and some methods did not work as well as initially expected (e.g. Boron-11, Mercury-199), while others (e.g. Boron-10) worked better than expected.

It was our intention not to duplicate previous results, but to use NMR to acquire new information that could be added to the existing wealth of information that could be used to better understand the catalyst system(s) involved in degrading TPB. However, to establish a basis for comparison to previous work, we first performed an experiment that essentially duplicated a previous one, to see if we could obtain the same basic answer by NMR methods as had been previously obtained using other analytical methods such as HPLC. Subsequently, we used NMR to uncover new information. 


\subsection{MATERIALS AND INSTRUMENTATION}

\subsubsection{Materials.}

Phenylborate Reagents: All phenylborate reagents werc obtained from Aldrich Chemical Company and were used as received. They include phenylboronic acid (97\%, lot no. JU 15003HS, “1PB"), diphenylborinic acid ethanolamine ester (98\%, lot no. CU 03002MR, “2PB"), triphenylborane-sodium hydroxide adduct (6 wt\% solution in water lot no. KR 09219HR, "3PB"), sodium tetraphenylborate $(99.5+\%$, lot no. LS $15123 \mathrm{AS})$, and sodium tetrakis(p-tolyl)borate (97\%, lot no. CU 00123BU).

Other solutions and reagents: All aqueous solutions were prepared using distilled, deionized water obtained from a Barnstead Nanopure filtering system (resistivity at least $18 \mathrm{M} \Omega$ $\mathrm{cm}$ ). The sodium hydroxide pellets, sodium nitrate, and potassium nitrate used to prepare all solutions were of reagent grade from EM Science. All other salts and solvents were reagent grade and were used as received.

\subsubsection{Nuclear Magnetic Resonance Spectrometry}

Nuclear Magnetic Resonance spectra were obtained on a Bruker Avance 400 wide-bore NMR spectrometer, operating at $42.989 \mathrm{MHz}$ for Boron-10. Other nuclei examined include proton $(400.13 \mathrm{MHz})$, and carbon-13 (100.61 MHz). For samples analyzed by Boron-10 NMR, samples from reaction vessels were first filtered through 0.45 micron nylon Gelman Acrodiscs, and then 2.2-mL aliquots were pipetted into 10-mm quartz NMR tubes (Wilmad Glass Co. cat. no. 7135PQ-200M). An insert (Wilmad Glass Co. cat. no. WGS-10BL-QTZ) containing either sodium borate ("borax", $\mathrm{Na}_{2} \mathrm{~B}_{4} \mathrm{O}_{7} \bullet 10 \mathrm{H}_{2} \mathrm{O}$, Mallinckrodt) in deuterium oxide, or neat deuterium oxide was placed inside the sample in the 10-mm, tube employed as an external deuterium lock. The sodium borate was used as a chemical shift reference (set to $0.0 \mathrm{ppm}$ ) and as an external integration standard where appropriate). When an insert was transferred from one tube to another, the outside of the insert was washed in a stream of distilled deionized water, then wiped dry with KimWipes® before placing it into another sample tube. The phenylborates appear in the -3.0 to $-20 \mathrm{ppm}$ range, when referenced against sodium borate. A $10-\mathrm{mm}$ broad band was used.

Peak assignments for the phenylborates in Boron-10 NMR were made by obtaining NMR spectra on the individual materials in $2 \mathrm{M} \mathrm{NaOH}$, and by reference to previously published chemical shifts [3]. The lower phenylborates ("1PB", "2PB", and "3PB") overlap considerably in the Boron-10 NMR, however it was still possible to tell relative differences in the amount of $\mathrm{Ph}_{3} \mathrm{~B}(\mathrm{OH})^{-}\left(3 \mathrm{~PB}\right.$, at -10 to $-11 \mathrm{ppm}$ relative to sodium borate), $\mathrm{Ph}_{2} \mathrm{~B}(\mathrm{OH})_{2}^{-}(2 \mathrm{~PB}$, at -8.5 to -9.3 
ppm relative to sodium borate), and $\mathrm{PhB}(\mathrm{OH})_{3}{ }^{-}(1 \mathrm{~PB}$, at -6.5 to $-8.0 \mathrm{ppm}$ relative to sodium borate).

Initially, Boron-11 NMR (128.377 MHz) was examined, but poor results were obtained due to a highly uneven baseline, particularly in the spectral region of interest. A bctter baseline was obtained using Boron-10 NMR, however the natural abundance of Boron-10 is only about $20 \%$, compared to $80 \%$ for Boron- 11 , and thus a greater number of scans were required to obtain an acceptable signal-to-noise ratio to obtain good peak integrals. Thus for certain experiments it was necessary to use sodium tetraphenylborate that was enriched in Boron-10 to improve the signal-to-noise ratio and reduce the time required to acquire the data. (The synthesis of NaTPB, isotopically enriched in Boron-10, is described below.) Toward the end of the studies reported here, acquisition parameters and baseline corrections were optimized, and good quality Boron-11 spectra were finally obtained. Any future studies will utilize Boron-11 NMR.

Palladium NMR was not investigated. The main reason was that the relaxation value of the only NMR-active nucleus Palladium-105 is below 10 microseconds, which results in extremely broad peaks [4]. In addition, the low concentration of palladium in the active catalyst systems (typically about 20 micromolar to one millimolar) along with a rather low natural abundance of Palladium-105 (22.2\%) led us to concentrate our efforts in other nucleus studies.

Attempts to obtain mercury NMR spectra were performed since it was reasonable to expect relatively narrow peaks for Mercury-199 (typical relaxation values between 10 milliseconds and one second) [4]. Concentrated aqueous solutions of mercury (II) nitrate and mercury (II) chloride were prepared but thus far a useful signal has not been obtained. Mercury-199 NMR was not further pursued mostly because of the low mercury concentrations in the active catalyst systems (typically 0.3 to one millimolar), that would make peak detection even more challenging.

\subsubsection{Synthesis of Labeled Materials}

For certain experiments it was deemed desirable to prepare tetraphenylborate salts that were enriched in a particular isotope. There are a number of ways to synthesize sodium tetraphenylborate, howcver the method we chose to exploit was based on the method reported by Wittig [5], which involves the reaction of phenylmagnesium bromide with boron trifluoride (usually as the diethylether adduct). The reaction pathway used is described in the scheme below, and involves the formation of phenylmagnesium bromide using the standard Grignard reaction [69]. 


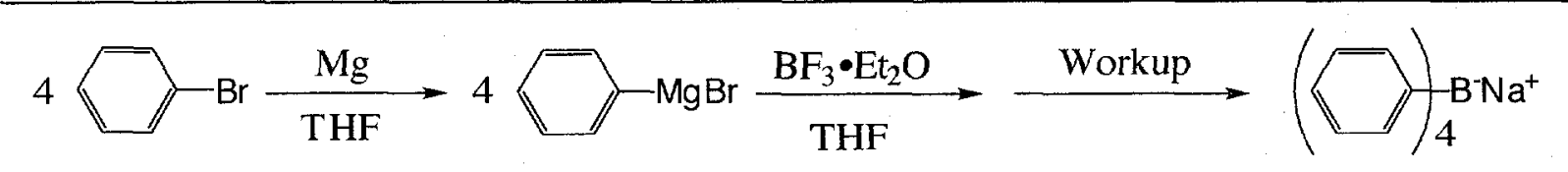

For one set of Boron-10 NMR experiments, NaTPB was prepared with a Boron-10 content of $99 \%$ using borontrifluoride diethyletherate that was $99 \%$ enriched in Boron-10. Where it is desirable to use NMR to trace the fate of the phenyl groups, the bromobenzene used can be labeled with deuterium, or the phenyl carbons can be enriched or depleted in Carbon-13. In anticipation of performing some experiments where the fate of the phenyl groups could be traced, NaTPB in which the phenyl groups contained deuterium in place of hydrogen was synthesized from deuterobromobenzene. While we did not get the opportunity to use the deuterated compound, its synthesis will still be described here.

\subsubsection{Reagents and solvents.}

The following reagents were used as received from the Sigma-Aldrich Chemical Company: bromobenzene- $\mathrm{d}_{5},(99.5$ atom $\% \mathrm{D})$, bromobenzene $(99 \%)$, tetrahydrofuran $(99.9 \%$ anhydrous inhibitor free, lot\# DU01559DU), magnesium turnings (98\%), boron trifluoride diethyletherate $\left[\mathrm{BF}_{3} \cdot \mathrm{Et}_{2} \mathrm{O}\right.$, lot \#s 05808KQ and 14419MU], and boron trifluoride diethyletherate 99 atom $\%{ }^{10} \mathrm{~B}$ ${ }^{10} \mathrm{BF}_{3} \cdot \mathrm{Et}_{2} \mathrm{O}$, lot \# 076H37531. EM Science was the source of sodium chloride (lot \# 36227639), acetone (99.5\%, lot \# 39293943) chloroform (lot \# 38258840), and dichloromethane (HPLC Grade, 99.8\%, lot \# 39078912). The following were purchased from J.T. Baker and used as received: hexanes (95\%, lot \# N11A28), and tetrahydrofuran (Baker Analyzed HPLC, lot \# N42313). Sodium carbonate, $99.5 \% \mathrm{NaCO}_{3}$,was provided by Baker \& Adamson-General Chem. Div. of Allied Chemical. Diethyl ether, absolute reagent ACS, 99\%, was obtained from VWR, and contained $1 \mathrm{ppm}$ 2,6-Di-tert-butyl-p-Cresol as peroxide inhibitor.

All aqueous solutions were prepared using distilled, deionized water obtained from a Barnstead Nanopure filtering system (resistivity at least $18 \mathrm{M} \Omega-\mathrm{cm}$ ).

\subsubsection{Major equipment.}

Major equipment used for this synthesis work included oil baths obtained from Ace Glass containing high temperature silica oil and controlled by a J-KEM Scientific Model 210 temperature controller. Rotary evaporation of solutions was undertaken with a Buchi R-114 Rotavapor fitted with a Buchi B480 Waterbath. A Brinkman WK230 Lauda Refrigerated Circulating Bath was used to circulate a $40 \%$ propylene glycol/water cooling fluid for use in the rotavapor condensers. Partial vacuum for the rotavapor was provided by a Buchi B-177 Vacobox fitted with a B720 
Vacuum Reducer. A Barnstead NANOpure II system was the source for distilled deionized 18 MQ-cm water. All reagents were weighed out on calibrated scales including a Mettler Toledo AG204, ID \# X-297111 (calibrated 1-14-00), and a Mettler PM400, ID \#X-173364 (calibrated 114-00).

\subsubsection{General apparatus configuration.}

The primary apparatus used for synthesizing the labeled compounds consisted of a $200 \mathrm{~mL}$ two-necked round-bottom flask fitted with a stir bar with a $50-100 \mathrm{~mL}$ capacity addition funnel on the angled neck and a jacketed condenser on the vertical neck. A WK230 Lauda Brinkman refrigerated circulating waterbath was used to circulate a 10 degree solution of $40 \%$ propylene glycol/water by volume to the condenser. An oil bath controlled by a J-Kem Scientific Model 210 controller provided constant heat to the reaction. A dry, inert atmosphere was maintained using an argon gas flow with the inlet through the addition funnel and the outlet through the condenser. An oil filled bubbler was located on the outlet side to monitor gas flow and prevent a backflow of air into the system.

All glassware was clean using a heated (60 degrees) sonicator bath and detergent. Sonicated glassware was rinsed with tap water, distilled water, $95 \%$ ethanol, and then acetone. The glassware was then oven dried overnight. Following assembly of the glassware into the apparatus needed for the chemical reaction it is placed under a flowing argon gas atmosphere and flame dried using a Bunsen burner.

\subsubsection{Synthesis of Sodium Tetraphenylborate-d20 $\left[\mathrm{NaB}\left(\mathrm{C}_{6} \mathrm{D}_{5}{ }_{4}\right]\right.$.}

The synthesis of this material is based on the procedure described by Williams et al. [10]. The primary apparatus was charged with $8.2356 \mathrm{~g}$ (0.339 moles) of magnesium turnings (using balance \#X-297111). These turnings were activated by stirring for 30 minutes at a moderate speed using a stir bar and a magnetic stir plate. Dry THF $(50 \mathrm{~mL})$ was then added using an oven dried syringe \& needle and using an argon filled balloon to place a positive pressure on the Sure/Seal ${ }^{\mathrm{TM}}$ bottle. Approximately $1 \mathrm{~mL}$ of bromobenzene- $\mathrm{d}_{5}$ was added using an oven-dried syringe. The reaction vessel was heated with a hot air gun to $\sim 45^{\circ} \mathrm{C}$ to initiate the Grignard reaction. Once started, as evidenced by appearance of color in the solution and gas generation, the remaining deutero-bromobenzene (a total of $50 \mathrm{~g}$ for this reaction, 0.038 moles, $32.5 \mathrm{~mL}$, lot no. $08162 \mathrm{MSDU}$, Aldrich) was added to the reaction dropwise ( $\sim 1$ drop / 5 seconds, over a total period of $2 \mathrm{hrs}$.) via the addition funnel. At this point the solution became very viscous so an oil bath, set at 70 degrees, was used to maintain reflux conditions through the rest of the synthesis. 
Borontrifluoride diethyletherate (lot \# 14419MU, $10.53 \mathrm{~g}, 0.0742$ moles, $9.40 \mathrm{~mL}$ ) was then added dropwise, via the addition funnel, to the reaction over a 50-minute time period. The reaction was run, at mild reflux, overnight, with stirring, using the oil bath set at $70^{\circ} \mathrm{C}$.

The reaction was stopped after about 18 hours by removing the heat source, and allowed to come to room temperature. The reaction mixture was then poured into $300 \mathrm{~mL}$ of $1.5 \mathrm{M} \mathrm{Na}_{2} \mathrm{CO}_{3}$ with rapid stirring. This removed the $\mathrm{Mg}^{2+}$ from solution as a $\mathrm{MgCO}_{3}$ precipitate. The $\mathrm{MgCO}_{3}$ was removed by filtration using a medium frit funnel. The $\mathrm{MgCO}_{3}$ was washed with $\sim 200 \mathrm{~mL}$ 50:50 ether/THF and this solvent mixture was pooled with the previous organic/aqueous filtrate.

The aqueous layer was isolated from the organic using a separatory funnel. The organic layer was washed with saturated salt water. The volatiles were removed from the organic layer by rotary evaporation under low ( $18 \mathrm{mbar}$ ) pressure using a $55^{\circ} \mathrm{C}$ water bath. The dried material was then dissolved in $65 \mathrm{~mL}$ of acetone and the liquid carefully decanted into a tared flask where it was reduced to dryness using a rotary evaporator under $18 \mathrm{mbar}$ pressure using a $55{ }^{\circ} \mathrm{C}$ water bath for 4.5 hours. With a formula weight of 362.38 , the 19.645 grams $(54.21 \mathrm{mmol})$ of product recovered represents a $73 \%$ yield. C-13 NMR revealed a very clean product that was in agreement with the expected structure for deuterated tetraphenylborate. ${ }^{13} \mathrm{C}\left\{{ }^{1} \mathrm{H}\right\}\left(100.61 \mathrm{MHz}, \mathrm{CDCl}_{3}\right): \delta$ $121.56\left(\mathrm{t}, J_{\mathrm{CD}}=23.4 \mathrm{~Hz}, \mathrm{ArC} 4\right), 125.31\left(\mathrm{t}, J_{\mathrm{CD}}=23.0 \mathrm{~Hz}, \mathrm{ArC} 2, \operatorname{ArC6}\right), 136.39\left(\mathrm{t}, J_{\mathrm{CD}}=\right.$ $23.2 \mathrm{~Hz}, \mathrm{ArC} 3, \mathrm{ArC} 5), 164.61\left(\mathrm{q}, J_{\mathrm{CB}-11}=49.3 \mathrm{~Hz}\right.$; septet, $\left.J_{\mathrm{CB}-10}=49.6 \mathrm{~Hz}, \mathrm{ArC1}\right)$.

A variety of other techniques were tried for isolating and purifying the final product. Initial efforts made to precipitate the product from the aqueous phase of the reaction by saturating the phase with $\mathrm{NaCl}$ proved ineffective. No product was recovered by this method. It is now thought that the ether present solubilizes the cations to the organic phase. Inverse solubility [10] was also tried as a means to purify the final product. Thus 3.01 grams of product was dissolved in $60 \mathrm{~mL}$

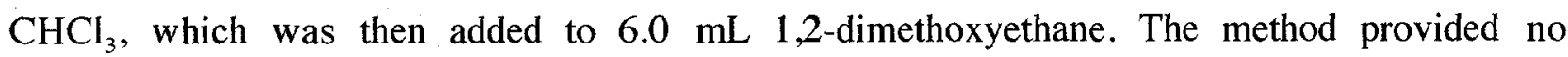
satisfactory results. Various attempts were also made at recrystallizing the product but, again, no satisfactory results were realized.

\subsubsection{First Synthesis of ${ }^{10} \mathrm{~B}$-enriched Sodium Tetraphenylborate.}

The primary apparatus was charged with $3.928 \mathrm{~g}(0.162 \mathrm{moles})$ of magnesium turnings (balance \#X-297111). The turnings were activated by stirring for 30 minutes at a moderate speed using a stir bar and a magnetic stir plate.

Dry THF $(40 \mathrm{~mL})$ was added to the apparatus using an oven dried syringe \& needle and using an argon filled balloon to place a positive pressure on the Sure/Seal ${ }^{\mathrm{TM}}$ bottle. Approximately $1 \mathrm{~mL}$ bromobenzene and heat was applied to the reaction vessel with a hot air gun to $\sim 45{ }^{\circ} \mathrm{C}$ to initiate the Grignard reaction. Once initialed, as evidenced by appearance of color in the solution and gas generation, the remaining bromobenzene (a total of $23.02 \mathrm{~g}$ for this reaction, 0.147 moles, 
$15.44 \mathrm{~mL}$, Aldrich) was added dropwise ( $\sim 1$ drop / 5 seconds, over a total period of $1.5 \mathrm{hrs}$.) to the reaction flask via the addition funnel.

Following the addition of the bromobenzene the flask was heated with an oil bath set at 70 ${ }^{\circ} \mathrm{C}$. The application of heat was continued through the rest of the synthesis.

Boron-10 trifluoride diethyletherate $\left({ }^{10} \mathrm{BF}_{3} \cdot \mathrm{Et}_{2} \mathrm{O}\right.$, Sigma Chemical Co. lot \# 076 H3753, 99 atom $\%, 5.0 \mathrm{~g}, 0.0352$ moles dissolved in $20 \mathrm{~mL}$ THF) was added dropwise, via the addition funnel, to the reaction over a 1 hour period of time. The reaction then proceeded, at mild reflux, over night, with stirring, using the oil bath set at $70^{\circ} \mathrm{C}$.

The reaction was stopped after $\sim 23$ hours by removing from heat, and bringing the apparatus to room temperature. The contents were then poured into $500 \mathrm{~mL}$ of $1.5 \mathrm{M} \mathrm{Na}_{2} \mathrm{CO}_{3}$ with rapid stirring. The resulting $\mathrm{MgCO}_{3}$ precipitate was removed by filtration using a medium frit funnel. The reaction flask was rinsed with $100 \mathrm{~mL}$ of 50:50 ether/THF, which was then used to wash $\mathrm{MgCO}_{3}$ precipitate. The flask was further washed with $100 \mathrm{~mL}$ distilled deionized water. The combined filtrates were refiltered using a medium frit funnel.

The organic layer isolated from the aqueous using a separatory funnel. The aqueous layer was washed with $\sim 200 \mathrm{~mL}$ of 50:50 ether/THF. This organic layer was isolated and combined with the first. The combined organic layers were reduced to dryness with a rotovapor resulting in a slightly tan colored solid product. With a formula weight of 361.57 the 11.747 grams (32.5 mmol) of crude product recovered. That portion of the crude product that was soluble in acetone was transferred to a clean, tared flask and reduced by rotary evaporation. Final yield of $11.696 \mathrm{~g}$ $(32.3 \mathrm{mmol})$ represented a final yield/recovery of $92 \%$.

Boron-10 NMR analysis of the product (acetone-d6) revealed a very clean product at $-12.745 \mathrm{ppm}$. A very minor boron-containing impurity $(0.0163$ relative to 1.000 main product) was observed at $\sim-6.6 \mathrm{ppm}$.

\subsubsection{Second Synthesis of ${ }^{10}$ B-enriched Sodium Tetraphenylborate.}

The flame-dried primary apparatus was charged with $7.8412 \mathrm{~g}(0.323 \mathrm{~mole})$ of magnesium turnings (balance \#X-297111). The turnings were then activated by stirring for 40 minutes at a moderate speed using a stir bar. Dry THF $(50 \mathrm{~mL})$ was then added to the apparatus using an oven dried syringe \& needle while employing an argon filled balloon to place a positive pressure on the Sure/Seal ${ }^{\mathrm{TM}}$ bottle.

Approximately $\sim 1 \mathrm{~mL}$ bromobenzene was then added and the reaction flask heated with a hot air gun to $\sim 45^{\circ} \mathrm{C}$ to initiate the Grignard reaction. Once started, as evidenced by appearance of color in the solution and gas generation, the remaining bromobenzene (a total of $46.02 \mathrm{~g}$ for this reaction, 0.293 moles, $30.87 \mathrm{~mL}$, Aldrich) was added dropwise ( $\sim 1$ drop / 5 seconds over a total period of $2 \mathrm{hrs}$.) to the reaction flask via the addition funnel. Following the bromobenzene addition 
the flask was heated with an oil bath set at $70^{\circ} \mathrm{C}$. The application of heat was continued through the rest of the synthesis.

Boron ${ }^{10} \mathrm{~B}$ trifluoride diethyletherate $\left({ }^{10} \mathrm{BF}_{3} \cdot \mathrm{Et}_{2} \mathrm{O}\right.$, Sigma Chemical Co. lot \# 076 $\mathrm{H} 3753$, 99 atom \%, $10.0 \mathrm{~g}, 0.07047$ mole dissolved in $30 \mathrm{~mL}$ THF) was added dropwise (1 drop every -6 seconds), via the addition funnel, to the reaction over a 2 hour period of time. The reaction was run, at mild reflux, over night, with stirring, using the oil bath set at $70^{\circ} \mathrm{C}$.

The reaction was stopped after $\sim 24$ hours by removing from heat, and bringing it to room temperature. This resulted in a very much-thickened solution that took on a pudding-like consistency. The reaction was returned to a solution state through the addition of $75 \mathrm{~mL} \mathrm{THF}$ and the simultaneous addition of heat via a heat gun. Magnesium was then removed from the solution by pouring the reaction into $\sim 550 \mathrm{~mL}$ of $1.5 \mathrm{M} \mathrm{Na}_{2} \mathrm{CO}_{3}$ with rapid stirring. The resulting $\mathrm{MgCO}_{3}$ precipitate was removed by filtration using a medium frit funnel. The reaction flask was rinsed with $25 \mathrm{~mL}$ of THF that was then used to wash the $\mathrm{MgCO}_{3}$ precipitate, which was further washed with an additional $100 \mathrm{~mL}$ THF. The combined filtrate was refiltered using a medium frit funnel.

The organic layer was isolated from the aqueous using a separatory funnel. The organic layer was then washed with $\sim 150 \mathrm{~mL}$ saturated salt water. The organic layer was again isolated from the aqueous layer through the use of a separatory funnel. This salt-saturated aqueous layer was then washed with $\sim 400 \mathrm{~mL}$ of hexanes. The hexanes layer was isolated and combined with the THF layer, then reduced by rotary evaporation. This product was then dissolved in acetone, transferred to a clean, tared flask and the contents reduced by rotory evaporation to yield a crude product of 21.450 grams $(59.32 \mathrm{mmol})$.

The crude product was dissolved in $100 \mathrm{~mL}$ methanol. A $20-\mathrm{mL}$ fraction of this was poured over a 20 -gram column of alumina that was packed in methanol. The product was washed from the column with $40 \mathrm{~mL}$ of methanol, followed by $50 \mathrm{~mL}$ of hexanes. The organic pass

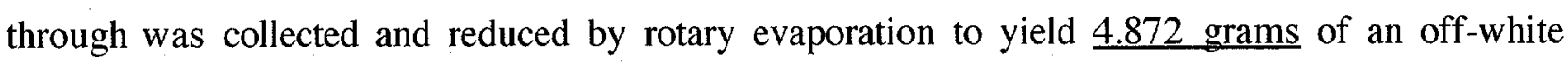
colored product identified as FVS060700-lot\#1. Boron-10 NMR (acetone-d6) revealed the desired product at $-12.7 \mathrm{ppm}$ (externally referenced against $\mathrm{BF}_{3}$ diethytletherate) with some minor impurities at $-3.0 \mathrm{ppm}(1.3 \%)$ and $-6.5 \mathrm{ppm}(1.8 \%)$ respectively.

The remaining $80 \mathrm{~mL}$ of methanol-dissolved crude product, exhibiting a pink coloration, was poured sequentially over 3 alumina columns of 20 grams of alumina each, then filtered via a fine-fritted funnel. When this solution was reduced to dryness and redissolved in $50 \mathrm{~mL}$ of methanol the pink coloration was still evident, so the solution was poured through a 50-gram alumina column that was rinsed with addition methanol. Following filtration via a fine-fritted funnel the solution was reduced by rotary evaporation to yield 11.544 grams of a cream-colored product identified as FVS060700-lot\#2. Boron-10 NMR (acetone-d6) identified a product similar 
to lot\#1, with the product at $-12.7 \mathrm{ppm}$ and two impurities at $-2.5 \mathrm{ppm}(1.8 \%)$ and $-7.0 \mathrm{ppm}$ $(2.1 \%)$.

The 50-gram alumina column was further rinsed with $40 \mathrm{~mL}$ of additional methanol, which was then filtered, and reduced to dryness to yield 1.718 grams of an off-white colored product identified as FV 5060700 -lot\#3. Boron-10 NMR (acetone-d6) identified the product peak at -12.7 ppm and impurities at $-1.8 \mathrm{ppm}(4.1 \%)$ and $-7.0 \mathrm{ppm}(1.2 \%)$.

The three combined lots made for a total recovered yield of 18.134 grams of product (50.15 mmol, $70.2 \%)$.

\subsection{TETRAPHENYLBORATE DEGRADATION USING PALLADIUM ON ALUMINA WITH DIPHENYLMERCURY}

\subsubsection{Introduction}

As a first step to determine whether boron NMR could be used to measure the rate of TPB degradation in an active catalyst system, a baseline reaction that had previously been conducted at SRS was repeated, so that the rate of degradation obtained by Boron-10 NMR could be compared to that obtained at SRS using HPLC as the analytical method (for the TPB and phenylborates present in the reaction mixture). The baseline system studied was the same as test numbers 10 and 11 from the "Synergism Phase A" tests performed at SRS [11], with the one deviation that only diphenyl mercury was used (the mercuric nitrate was excluded).

\subsubsection{Experimental}

Preparation of Stock Solutions. The stock solutions were prepared following the procedures obtained from SRS. All reagents used to prepare these solutions are as described above in section 2.2.1. The "Active Organics" (1PB/2PB/3PB) stock solution was prepared at 50$\mathrm{mL}$ scale (half of the procedure scale) in a Nalgene $50-\mathrm{mL}$ polypropylene volumetric flask by first dissolving $2.02 \mathrm{~g}$ of $\mathrm{NaOH}$ pellets in $25 \mathrm{~mL}$ water, followed by adding $0.635 \mathrm{~g}$ of phenylboronic acid, $0.773 \mathrm{~g}$ of diphenylborinic acid-ethanolamine ester, and $17.85 \mathrm{~g}$ of triphenylboron sodium hydroxide adduct (this last reagent is a slurry which needs to be well agitated before use). The flask is then diluted to the mark with water. The "NaTPB Cold Feed Solution" was prepared as described in the SRS procedure, but again at $50-\mathrm{mL}$ scale instead of $100-\mathrm{mL}$ scale. For this preparation however, the Boron-10 enriched TPB was also used. The solution was prepared by 
dissolving $4.61 \mathrm{~g}$ of $99 \% \mathrm{~B}-10$ enriched NaTPB (synthesis described above) with $4.62 \mathrm{~g}$ of Aldrich NaTPB $(\sim 20 \% \mathrm{~B}-10)$ with $0.196 \mathrm{~g}$ of $\mathrm{NaOH}$ in $50 \mathrm{~mL}$ water in a $560-\mathrm{mL}$ Nalgene ${ }^{\circledR}$ polypropylene volumetric flask. The concentration of TPB is thus $0.54 \mathrm{M}$, with a B-10 content of nearly $60 \%$. The final stock solution prepared was the " $2.5 \mathrm{M} \mathrm{Na}^{+}, 5000 \mathrm{mg} / \mathrm{L} \mathrm{NaTPB}, 1 \mathrm{wt} \%$ KTPB Slurry" ("Stock Slurry"), following the SRS procedure at one-quarter scale (500 $\mathrm{mL}$ was prepared instead of 2 liters). The solution was prepared by first dissolving $0.783 \mathrm{~g}$ of potassium nitrate into $175 \mathrm{~g}$ of water in a $73.767 \mathrm{~g} 1-\mathrm{L}$ Nalgene polypropylene bottle, and then with stirring (stirbar mass $6.945 \mathrm{~g}$ ), adding $21.678 \mathrm{~g}$ of the previously prepared "NaTPB Cold Feed Solution" slowly in portions over a period of about 45 minutes. Additional water $(50 \mathrm{~g})$ was added to the bottle, and the white slurry in the capped bottle was then stirred overnight. The next day, $24.380 \mathrm{~g}$ of $\mathrm{NaOH}$ was added portion-wise while cooling the bottlc as per the procedure, followed by an additional $6.76 \mathrm{~g}$ of water. The mass of the bottle contents was $278.75 \mathrm{~g}$ at this stage. The contents (similar to a "milkshake" in appearance) were stirred overnight, and then used to make up the baseline catalyst system.

An attempt was made to prepare the analogous "NaTPB Cold Feed Solution" using sodium tetrakis ( $p$-tolyl)borate, but this material proved to be too insoluble in aqueous solution. One of the degradation products of TPB is phenol; theoretically degradation of the tolyl derivative of TPB should give rise to a cresol. Of interest was finding out whether the hydroxyl group on the aromatic ring is attached to the carbon originally attached to boron. For the cresol derivative, the orientation of the methyl group to the hydroxyl group (whether it was ortho, meta, or para) could help answer this question (i.e., if para-cresol was formed, then the hydroxyl would be attached to the same aromatic ring carbon originally attached to boron). However due to the low solubility of sodium tetrakis( $p$-tolyl)borate it was not possible to perform this particular experiment.

Other Reagents. Palladium on alumina was obtained from SRS $(0.5 \% \mathrm{Pd}$ on alumina pellets, Alfa Products lot no. 082378). The pellet material necessary for a particular experiment was ground to a fine powder using an agate mortar and pestle. Diphenyl mercury was obtained from Aldrich Chemical Company (lot no. KU 08813E2). (Caution: diphenyl mercury is highly toxic! Handle carefully!)

Reaction Bottles. Teflon ${ }^{\circledR}$ PFA bottles $(250 \mathrm{~mL}$, Norton, Performance Plastics, catalog no. A 1069591), were used for all reactions. The bottles were cleaned prior to use by rinsing twice with distilled, deionized water, twice with $95 \%$ ethanol, twice with acetone, then dried under a stream of argon. The bottles contain a solid white Teflon ${ }^{\circledR}$ (PTFE) 32-mm wide cover disc that fits snugly over the lip of the bottle, and a Teflon ${ }^{\circledR}$ PFA screw cap that threads onto the bottle and secures the PTFE disc to the bottle. A recession of diameter $20 \mathrm{~mm}$ was drilled in the center of the PTFE disc to a depth of $3 \mathrm{~mm}$ (about halfway through the disc). A 5-mm wide hole was then drilled completely through the center of the recession in the PTFE disc. The recession can 
accommodate the insertion of a 20-mm wide silicone septum (thickness $3.5 \mathrm{~mm}$, hence the septum extends about $0.5 \mathrm{~mm}$ above the face of the cap). The silicone septum (Wheaton no. 224173) has a PTFE liner on one face, and is fitted into the recession so that the PTFE liner covers the hole and thus faces the interior of the bottle. The screw cap lid of the bottle was also drilled through with a hole of diameter $5 \mathrm{~mm}$. The screw cap lid secures the PTFE cover disc with inserted septum to the bottle. A needle can be pushed through the hole in the screw cap, through the septum, and can reach any liquid contents inside the bottle.

Baseline catalyst system. As mentioned above, the baseline system studied was the same as test numbers $10 \& 11$ from the "Synergism Phase A" tests performed at SRS, with the one deviation that no mercuric nitrate was used. A $250-\mathrm{mL}$ Tefon® PFA bottle modified as described above was flushed for about $5 \mathrm{~min}$ with a stream of argon, and then charged with $177.06 \mathrm{~g}$ of the "Stock Slurry" solution, $1.00 \mathrm{~mL}$ of the "Active Organics" solution, $0.052 \mathrm{~g}$ of the ground Alfa Products $0.5 \%$ Pd on alumina, $0.0163 \mathrm{~g}$ of diphenyl mercury, and 82 microliters of benzene. The bottle was then flushed again with argon for three minutes, then capped and shaken and swirled for 30 seconds. A sample for the zero-point was removed following the sampling procedure below, and then the bottle was placed in a Precision Scientific Model 14EG convection oven set at $45^{\circ} \mathrm{C}$. The bottle was not agitated while in the oven.

Sampling. To obtain samples for NMR analysis, the $250-\mathrm{mL}$ reaction bottle was removed from the $45^{\circ} \mathrm{C}$ oven, and allowed to cool for 15-20 minutes. A 2-inch needle attached to an Argon inlet was inserted into the septum, and a 6-inch stainless steel 18 -gauge syringe needle attached (Aldrich catalog no. Z10271-7) attached via a Luer hub to a 5-mL all-polypropylene/polyethylene disposable syringe (Aldrich Fortuna ${ }^{\circledR}$ brand catalog no. Z11686-6) was inserted through the septum, and about $3 \mathrm{~mL}$ of slurried sample was removed (the solution was swirled before sampling). The needle was then raised above the solution level, and about $1-2 \mathrm{~mL}$ of the bottle atmosphere (essentially argon with perhaps some benzene) was also pulled into the syringe before removing the syringe needle from the bottle. The syringe was turned upright to prevent leakage and the needle was replaced with a 13 -mm 0.45 micron nylon Gelman Acrodisc filter, and the liquid was pushed through the filter into an 8 -mL Nalgene polypropylene bottle. The argon inlet was removed from the reaction bottle, which was then placed back into the $45^{\circ} \mathrm{C}$ oven. The time out of the oven was typically about 30 minutes, and only the actual time the bottle was in the oven was recorded for the kinetic measurements. A 2.2-mL aliquot of sample was then removed from the bottle using a 2.5-adjustable Eppendorf pipet, and placed into a 10-mm quartz NMR tube and the Boron-10 NMR spectrum obtained as described above in section 2.2.2. 


\subsubsection{Results and Discussion}

Boron-10 NMR successfully monitored the decrease in the tetraphenylborate resonance and the ingrowth (over the amount initially present) of the lower phenylborates. The reaction bottle was sampled as described above at intervals shown in Table 1. The Boron-10 NMR spectrum were recorded and the TPB peak (typically at -16.3 to $-17.3 \mathrm{ppm}$ relative to sodium borate), and the lower phenylborate peaks (spanning about -5 to $-15 \mathrm{ppm}$ ) were integrated. The spectrum taken prior to the start of the reaction shows the amount of phenylborates already present in the system from the addition of the "Active Organics" system. The percent TPB present at the start of the reaction was $67.5 \%$ on average, and the amount of TPB measured relative to the lower phenylborates during the reaction was normalized against this value. It was unnecessary to adjust for the difference in the Boron-10 content between the TPB and lower phenylborates present at the start of the reaction, since the ingrowth of the lower phenylborates after time zero is derived from the decrease in the (Boron-10 enriched) TPB peak.

A plot of the data along with the data previously obtained at SRS for the decrease in the amount of TPB present as a function of time is shown in Figure 1. It can be seen that the overall rate of TPB degradation obtained using the NMR methods is similar to that previously obtained at SRS [11]. The rate of ingrowth of the individual phenylborates is difficult to quantify due to peak overlap and the difficulty in subtracting out the amount of each component present at the start of the reaction, but it does appear that $3 \mathrm{~PB}$ grows in during the course of the reaction. The spectra obtained for this reaction used to plot the data are in contained in supplementary material.

Table 1. TPB Degradation NMR Data for Baseline System

\begin{tabular}{|l|l|l|l|l|}
\hline $\begin{array}{l}\text { Time } \\
(\text { Hours }) \\
\text { at } 45{ }^{\circ} \mathbf{C}\end{array}$ & $\begin{array}{l}\text { TPB integral } \\
\text { (raw data) }\end{array}$ & $\begin{array}{l}\text { Lower } \\
\text { Phenylborates } \\
\text { integral } \\
\text { (raw data) }\end{array}$ & Percent TPB & $\begin{array}{l}\text { Percent TPB } \\
\text { remaining } \\
\text { (normalized for } \\
\text { start of reaction) }\end{array}$ \\
\hline 0 & $2.1663 ; 1.8913$ & $1.0665 ; 0.8863$ & $\begin{array}{l}67.0 \% ; 68.1 \% \\
(\text { avg. }=67.5 \%)\end{array}$ & $100 \%$ \\
\hline 24 & $1.4596 ; 1.0735$ & $1.4898 ; 1.0057$ & $\begin{array}{l}57.6 \% ; \quad 59.7 \% \\
(\text { avg. = 58.6\%) }\end{array}$ & $86.8 \%$ \\
\hline 158 & 0.8909 & 1.8036 & $33.1 \%$ & $49.0 \%$ \\
\hline 216 & 0.4320 & 2.4086 & $15.2 \%$ & $22.5 \%$ \\
\hline 314 & 0.0104 & 3.0062 & $0.34 \%$ & $0.51 \%$ \\
\hline
\end{tabular}




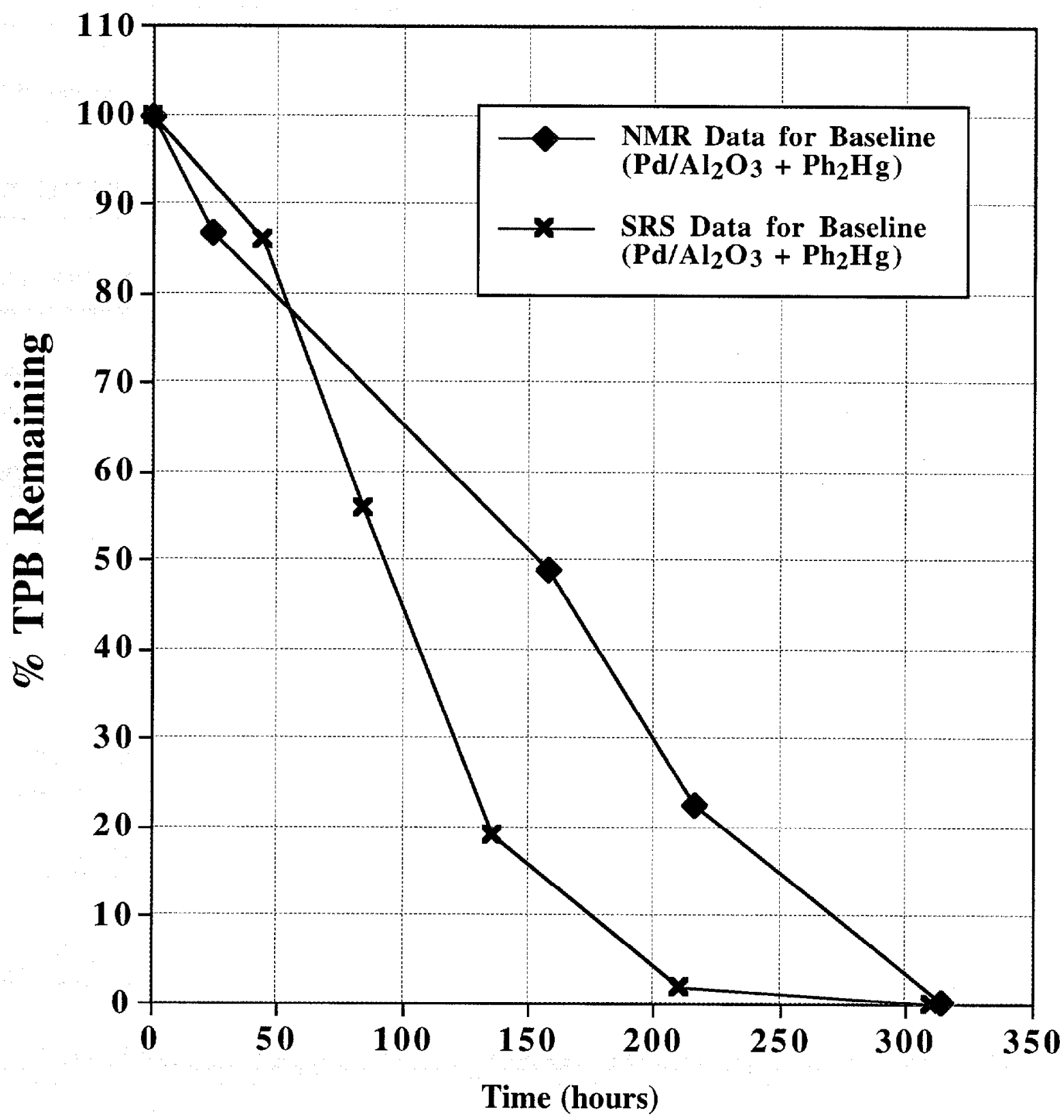

?

Figure 1. Comparison of TPB degradation for baseline catalyst case for data obtained by NMR with data previously obtained at SRS. 


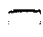




\subsection{TETRAPHENYLBORATE DEGRADATION USING PALLADIUM NITRATE AND VARIOUS MERCURY COMPOUNDS}

\subsubsection{Introduction}

The catalytic activity of palladium in the degradation of TPB had previously been verified [2], and further studies at SRS found that mercury appeared to be involved in the active catalyst system. Plausible mechanisms showing the involvement of both palladium and mercury in the degradation of TPB were put forth by Professor J. M. Boncella of the University of Florida at the Consultant Meeting held at SRS during May 10-11, 2000 [11]. However the precise role of mercury and the nature of the active catalyst remain unclear. Thus one of the objectives of the next series of experiments was to obtain more insight as to the role of mercury. Topics of interest include whether TPB degradation can be catalyzed by palladium in the absence of mercury, and, if so, how that reaction rate and mechanism differs from that observed when mercury is present. Another question of interest is the dependency of catalyst activity on such factors as the chemical form of mercury and palladium, the presence or absence of oxygen (and radiation), and the presence of other species such as benzene and phenylborates (are special conditions required to generate the most active catalysts, and what are those conditions?). Are the catalytic reactions largely heterogeneous, occurring only on a metal cluster or supported metal surface, or is there a homogeneous component to the catalysis perhaps required for activation? Other related questions, which were beyond the scope of this initial work, include the possible role of other metals that may be present in the waste tanks.

Toward obtaining some insight into the role of mercury, a series of simple tests were conducted in which sodium tetraphenylborate was partially dissolved at 1 millimolar in $2 \mathrm{M} \mathrm{NaOH}$, and palladium with and without various mercury compounds added. The disappearance of TPB and the ingrowth of tetraphenylborate degradation products (lower phenylborates) were then measured using Boron-10 NMR.

\subsubsection{Experimental}

Reagents. Palladium nitrate was $99.999 \%$ as a $10 \mathrm{wt} \%$ solution in $10 \mathrm{wt} \%$ nitric acid (Aldrich, lot no. AI $11519 \mathrm{MU}$ ). The following mercury compounds were employed: mercuric nitrate (Aldrich lot no. $08902 \mathrm{HS} ; 0.145 \mathrm{M}$ solution in water); phenyl mercuric nitrate basic (Aldrich lot no. $\mathrm{Cl} 04312 \mathrm{TR} ; \mathrm{PhHgNO}_{3} \cdot \mathrm{PhHgOH}$ ); and diphenyl mercury (Aldrich lot no. $\mathrm{KU}$ 
08813E2). (Caution: mercury compounds, particularly diphenyl mercury, are highly toxic!) Sodium tetraphenylborate used was Aldrich $99.5 \%$ (lot no. LS15123AS). Other reagents were as previously described above in section 2.2.1.

Procedure. (See Table 2 for a report of the materials and amounts used in each reaction bottle.) Five labeled reaction bottles outfitted as described in section 2.3.2 were flushed with argon, then charged with $1.7 \mathrm{~g}$ of Aldrich $99.5 \%$ sodium tetraphenylborate, then placed back under argon. The concentration of TPB in this experiment was sufficiently high such that natural abundance Boron- 10 could be used. Accurately weighed $50 \mathrm{~g}$ portions of $2.0 \mathrm{M} \mathrm{NaOH}$ solution, which had been prepared using argon-sparged water, were then added to each bottle. The bottles were placed under argon again, and swirled and shaken for several minutes to dissolve most of the NaTPB. (General note: Whenever the bottles were opened to add reagents, the bottles were flushed briefly with a slow stream of argon, then capped before the next reagent addition, to minimize the oxygen concentration.) The palladium nitrate solution was then added to bottles $1-4$, and the bottles swirled under argon. A greyish-brown precipitate was observed to form immediately. The mercury compounds were then added to the appropriate bottle as described in Table 2, and placed back under argon. Thus, the solutions contained about 100 millimolar TPB, and about 1 millimolar each palladium and/or mercury. Bottle \#1 contained only palladium, and bottle \#5 contained only mercury. The bottles were swirled and shaken for a few minutes, then placed in a $45{ }^{\circ} \mathrm{C}$ oven in the manner described previously above. Aliquots were removed from each bottle at various times $(17,89,163$, and 310 hours, see Table 3 ) for Boron-10 NMR analysis also in the manner previously described in section 2.3.2.

Samples examined prior to placing the bottles in the $45^{\circ} \mathrm{C}$ oven, at 17 hours, and at 89 hours, Boron-10 NMR spectra were acquired with an insert in the tube containing sodium borate in deuterium oxide as a chemical shift reference (boron peak in sodium borate set to $0.0 \mathrm{ppm}$ ) and as an external integration standard. However, as the phenylborate degradation products grew in, it was found that the shoulder of sodium borate peak and the shoulder of the 1PB peak overlapped enough to affect the integration of the $1 \mathrm{~PB}, 2 \mathrm{~PB}$, and 3PB peaks. Hence, starting with the samples taken at 89 hours, data were acquired for all subsequent time points (163 hour and 310 hour samples) with only deuterium oxide in the insert. Spectra were periodically acquired with the sodium borate insert to check mass balance. Within experimental error, it appears that there may have been a slight reduction in total boron mass balance (ratio of total phenylborates including TPB to sodium borate) between the start of the reaction and 17 hours, but from 17 hours on, the mass balance appears to have been largely conserved.

It is unclear whether "OPB" (tetrahydroxyborate, $\mathrm{B}(\mathrm{OH})_{4}^{-}$) was formed during the reaction. It is believed that the boron peak for OPB would fall near that of sodium borate (near 0 ppm), but that would need to be checked in future work. 
Table 2. Conditions Matrix for Pd/Hg Catalyst Experiments

\begin{tabular}{|c|c|c|c|c|c|}
\hline \multicolumn{5}{|l|}{ Amount of reagent added to each bottle } \\
\hline $\begin{array}{c}\text { Chemical } \\
(\text { moles added })\end{array}$ & Bottle 1 & Bottle 2 & Bottle 3 & Bottle 4 & Bottle 5 \\
\hline $\begin{array}{c}2 \mathrm{M} \mathrm{NaOH} \\
\text { solution }\end{array}$ & $50.04 \mathrm{~g}$ & $50.03 \mathrm{~g}$ & $50.19 \mathrm{~g}$ & $50.07 \mathrm{~g}$ & $50.13 \mathrm{~g}$ \\
\hline $\begin{array}{c}\mathrm{NaTPB} \\
(5.0 \mathrm{E}-03)\end{array}$ & $1.708 \mathrm{~g}$ & $1.709 \mathrm{~g}$ & $1.706 \mathrm{~g}$ & $1.707 \mathrm{~g}$ & $1.705 \mathrm{~g}$ \\
\hline $\begin{array}{c}\mathrm{Pd}\left(\mathrm{NO}_{3}\right)_{2} 10 \mathrm{wt} \% \text { in } \\
10 \mathrm{wt} \% \text { nitric acid } \\
(4.3 \mathrm{E}-05)\end{array}$ & $0.100 \mathrm{~mL}$ & $0.100 \mathrm{~mL}$ & $0.100 \mathrm{~mL}$ & $0.100 \mathrm{~mL}$ & $* * * * *$ \\
\hline $\begin{array}{c}\mathrm{Hg}\left(\mathrm{NO}_{3}\right)_{2}, \\
0.145 \mathrm{M} \mathrm{in} \mathrm{water}_{(5.0 \mathrm{E}-05)}\end{array}$ & $* * * * *$ & $0.345 \mathrm{~mL}$ & $* * * * *$ & $* * * * *$ & $* * * * *$ \\
\hline $\begin{array}{c}\mathrm{PhHgNO}{ }_{3} \bullet \mathrm{PhHgOH} \\
(2.44 \mathrm{E}-05 ; \\
4.88 \mathrm{E}-05 \mathrm{~mole} \mathrm{Hg})\end{array}$ & $* * * * *$ & $* * * * *$ & $0.0155 \mathrm{~g}$ & $* * * * *$ & $0.0155 \mathrm{~g}$ \\
\hline $\begin{array}{c}\mathrm{Ph}_{2} \mathrm{Hg} \\
(5.36 \mathrm{E}-05)\end{array}$ & $* * * * *$ & $* * * * *$ & $* * * * *$ & $0.0190 \mathrm{~g}$ & $* * * * *$ \\
\hline
\end{tabular}

\subsubsection{Results and Discussion}

It was of interest to see whether palladium alone could catalyze the degradation of TPB, and if so, to compare the rate of degradation and degradation product distribution with that obtained in systems containing palladium and various forms of mercury. Five different systems were examined: the reagents and the amounts added are shown in Table 2 . The system essentially consisted of NaTPB at about $0.1 \mathrm{M}$ in $2 \mathrm{M} \mathrm{NaOH}$, with a metal catalyst, where each metal ion was present roughly equimolar amounts at about $0.001 \mathrm{M}$. The five reactions examined, as shown in Table 3, included palladium nitrate only (Bottle \#1), palladium nitrate plus mercuric nitrate (Bottle \#2), palladium nitrate plus phenylmcrcuric nitrate basic $\left(\mathrm{PhHgNO}_{3} \bullet \mathrm{PhHgOH}\right.$, Bottle \#3), palladium nitrate plus diphenylmercury (Bottle \#4), and phenylmercuric nitrate basic alone (Bottle $\# 5$, same as Bottle \#3 except no palladium). 
Table 3. TPB Degradation NMR Data for Pd/Hg Catalyst Systems

\begin{tabular}{|c|c|c|c|c|c|}
\hline \multirow{2}{*}{$\begin{array}{l}\text { Integral Data and } \\
\text { Component Fraction } \\
\text { Calculations } \\
\text { Time (hours) at } 45{ }^{\circ} \mathbf{C} \\
\text { integral at } 17 \text { hours } \\
\text { integral at } 89 \text { hours } \\
\text { fraction each at } 89 \text { hours } \\
\text { integral at } 163 \text { hours } \\
\text { fraction each at } 163 \text { hours } \\
\text { integral at } 310 \text { hours } \\
\text { fraction each at } 310 \text { hours } \\
\end{array}$} & \multirow{2}{*}{\begin{tabular}{|c|} 
Bottle \#1 \\
1 P B \\
0 \\
0.2422 \\
0.1791 \\
0.5360 \\
0.2901 \\
0.6621 \\
0.2110 \\
\end{tabular}} & \multicolumn{2}{|c|}{ Pd nitrate only } & \multirow[b]{2}{*}{$\begin{array}{c}\text { TPB } \\
1 \\
1.0000 \\
0.7395 \\
1.0000 \\
0.5412 \\
1.0000 \\
0.3187\end{array}$} & \multirow[b]{2}{*}{$\begin{array}{c}1 / 2 / 3 \text { P B } \\
0 \\
0.3523 \\
0.2605 \\
0.8477 \\
0.4588 \\
2.1373 \\
0.6813 \\
\end{array}$} \\
\hline & & $\begin{array}{c}\text { 2PB } \\
0 \\
0.0606 \\
0.0448 \\
0.2352 \\
0.1273 \\
1.3358 \\
0.4258 \\
\end{array}$ & $\begin{array}{c}3 \mathbf{P B} \\
0 \\
0.0495 \\
0.0366 \\
0.0766 \\
0.0414 \\
0.1394 \\
0.0444\end{array}$ & & \\
\hline $\begin{array}{l}\text { Time (hours) at } 45{ }^{\circ} \mathbf{C} \\
\text { integral at } 17 \text { hours } \\
\text { integral at } 89 \text { hours } \\
\text { fraction each at } 89 \text { hours } \\
\text { integral at } 163 \text { hours } \\
\text { fraction each at } 163 \text { hours } \\
\text { integral at } 310 \text { hours } \\
\text { fraction each at } 310 \text { hours }\end{array}$ & $\begin{array}{c}\text { Bottle \#2 } \\
\text { 1 P B } \\
0 \\
0.2994 \\
0.1988 \\
0.5542 \\
0.3115 \\
0.6803 \\
0.2758\end{array}$ & $\begin{array}{c}\text { Pd } \\
\text { nitrate } \\
\text { 2P B } \\
0 \\
0.0544 \\
0.0361 \\
0.1317 \\
0.0740 \\
0.7059 \\
0.2862 \\
\end{array}$ & $\begin{array}{c}\mathbf{H g} \text { nitrate } \\
\text { 3 P B } \\
0 \\
0.1524 \\
0.1012 \\
0.0933 \\
0.0524 \\
0.0802 \\
0.0325 \\
\end{array}$ & $\begin{array}{c}\text { TPB } \\
1 \\
1.0000 \\
0.6639 \\
1.0000 \\
0.5621 \\
1.0000 \\
0.4054 \\
\end{array}$ & $\begin{array}{c}1 / 2 / 3 \text { P B } \\
0 \\
0.5062 \\
0.3361 \\
0.7792 \\
0.4379 \\
1.4680 \\
0.5948\end{array}$ \\
\hline $\begin{array}{l}\text { Time (hours) at } 45{ }^{\circ} \mathrm{C} \\
\text { integral at } 17 \text { hours } \\
\text { integral at } 89 \text { hours } \\
\text { fraction each at } 89 \text { hours } \\
\text { integral at } 163 \text { hours } \\
\text { fraction each at } 163 \text { hours } \\
\text { integral at } 310 \text { hours } \\
\text { fraction each at } 310 \text { hours }\end{array}$ & $\begin{array}{c}\text { Bottle } \# 3 \\
\text { 1PB } \\
0 \\
0.2174 \\
0.1538 \\
0.3813 \\
0.2143 \\
0.7619 \\
0.2778 \\
\end{array}$ & \begin{tabular}{|c|c|} 
Pd & nitrate \\
2 P B \\
0 \\
0.0456 \\
0.0323 \\
0.1089 \\
0.0612 \\
0.1905 \\
0.0694 \\
\end{tabular} & $\begin{array}{c}\mathrm{PhHgNO} \cdot \mathrm{P} \\
\text { 3 P B } \\
0 \\
0.1500 \\
0.1061 \\
0.2887 \\
0.1623 \\
0.7905 \\
0.2882 \\
\end{array}$ & $\begin{array}{c}\mathrm{IgOH} \\
\text { TPB } \\
1 \\
1.0000 \\
0.7077 \\
1.0000 \\
0.5621 \\
1.0000 \\
0.3646 \\
\end{array}$ & $\begin{array}{c}1 / 2 / 3 \text { P B } \\
0 \\
0.4130 \\
0.2923 \\
0.7789 \\
0.4379 \\
1.7429 \\
0.6354 \\
\end{array}$ \\
\hline $\begin{array}{l}\text { Time (hours) at } 45{ }^{\circ} \mathbf{C} \\
\text { integral at } 17 \text { hours } \\
\text { integral at } 89 \text { hours } \\
\text { fraction each at } 89 \text { hours } \\
\text { integral at } 163 \text { hours } \\
\text { fraction each at } 163 \text { hours } \\
\text { Deconvolute integral at } 163 \\
\text { fraction each at } 163 \text { hours } \\
\text { integral at } 310 \text { hours } \\
\text { fraction each at } 310 \text { hours }\end{array}$ & \begin{tabular}{|c} 
Bottle \#4 \\
1 P B \\
0 \\
0.4927 \\
0.2772 \\
2.6699 \\
0.5335 \\
2.6630 \\
0.5321 \\
0.7228 \\
0.7228 \\
\end{tabular} & $\begin{array}{c}\text { Pd } \\
\text { nitrate } \\
\text { 2PB } \\
0 \\
0.0821 \\
0.0462 \\
0.4596 \\
0.0918 \\
0.4690 \\
0.0937 \\
0.2554 \\
0.2554 \\
\end{array}$ & $\begin{array}{c}\text { Ph2Hg } \\
\text { 3PB } \\
0 \\
0.2026 \\
0.1140 \\
0.8754 \\
0.1749 \\
0.8730 \\
0.1744 \\
0.0217 \\
0.0217 \\
\end{array}$ & $\begin{array}{c}\text { TPB } \\
1 \\
1.0000 \\
0.5626 \\
1.0000 \\
0.1998 \\
1.0000 \\
0.1998 \\
0.0000 \\
0.0000 \\
\end{array}$ & $\begin{array}{c}1 / 2 / 3 P \text { B } \\
0 \\
0.7774 \\
0.4374 \\
4.0048 \\
0.8002 \\
4.0048 \\
0.8002 \\
1.0000 \\
1.0000 \\
\end{array}$ \\
\hline $\begin{array}{l}\text { Time (hours) at } 45{ }^{\circ} \mathbf{C} \\
\text { integral at } 17 \text { hours } \\
\text { integral at } 89 \text { hours } \\
\text { fraction each at } 89 \text { hours } \\
\text { integral at } 163 \text { hours } \\
\text { fraction each at } 163 \text { hours } \\
\text { integral at } 310 \text { hours } \\
\text { fraction each at } 310 \text { hours }\end{array}$ & $\begin{array}{c}\text { Bottle \#5 } \\
\text { 1 P B } \\
0 \\
0 \\
0 \\
0 \\
0 \\
0 \\
0\end{array}$ & \begin{tabular}{|c|} 
PhHgNO3 P \\
2 P B \\
0 \\
0 \\
0 \\
0 \\
0 \\
0 \\
0
\end{tabular} & $\begin{array}{c}\text { OH only } \\
\text { 3 P B } \\
0 \\
0 \\
0 \\
0 \\
0 \\
0 \\
0\end{array}$ & $\begin{array}{c}\text { Pd) } \\
\text { TP B } \\
1 \\
1 \\
1 \\
1 \\
1 \\
1 \\
1\end{array}$ & $\begin{array}{c}1 / 2 / 3 P \text { B } \\
0 \\
0 \\
0 \\
0 \\
0 \\
0 \\
0\end{array}$ \\
\hline
\end{tabular}


Aliquots were removed from each bottle for Boron-10 analysis using the procedure previously described after 17 hours, 89 hours, 163 hours, and 310 hours at $45^{\circ} \mathrm{C}$. At 17 hours, no detectable quantities of phenylborate degradation products were observed for any of the five reactions; only the TPB peak was observed. (Relevant NMR spectra in contained in the supplementary material.) However after 89 hours, peaks attributable to phenylborate degradation products (1PB, 2PB, 3PB) were observed in all bottles containing palladium, but not in bottle \#5, which contained only mercury. After 163 hours, it appeared that the rate of TPB degradation was about the same for bottle numbers 1-3; bottle \#4 containing palladium plus diphenylmercury displayed a faster rate of TPB degradation, and bottle \#5 again showed essentially no decomposition (perhaps a trace). After 310 hours, all the TPB in bottle \#4 was gone.

The phenylborate peaks were carefully integrated, and a ruler was used to measure the portion of the integral that was attributable to each species (1PB or $2 \mathrm{~PB}$ or $3 \mathrm{~PB}$ ). The fractional integral data and the calculations to give the fraction of each phenylborate (1PB, 2PB, 3PB, TPB) in the reaction mixture are shown in Table 3, and the distribution of all the phenylborates for each reaction for the 89,163 , and 310 hour data are plotted in Figure 2. A mathematical deconvolution of the individual peaks attributable to $1 \mathrm{~PB}, 2 \mathrm{~PB}, 3 \mathrm{~PB}$ was performed by transferring the raw $\mathrm{x}, \mathrm{y}$ point data for the spectrum for the palladium plus diphenylmercury 163 hour data to an Excel@ spreadsheet and applying a gaussian curve fitting routine to the peak data. The ratio of the peak areas obtained for $1 \mathrm{~PB}, 2 \mathrm{~PB}$, and $3 \mathrm{~PB}$ were found to be virtually identical to that obtained by direct measurement of the raw integral data. The fraction of each phenylborate species obtained using the mathematically deconvolution method is also shown in Table 3 for bottle \#4 at 163 hours.

In Figure 3, the rate of TPB decomposition only is plotted for all five reactions, along with the rate of TPB decomposition from the baseline systems which used palladium on alumina with diphenylmercury as the catalyst system (both ORNL and SRS data shown previously in Figure 1) for comparison. It can be seen that the rate of TPB degradation for bottle reactions 1-3 are essentially the same (the uncertainty in the data is $\pm 5 \%$ ). Thus, it appears that under these experimental conditions, the addition of mercuric nitrate or $\mathrm{PhHgNO}_{3} \cdot \mathrm{PhHgOH}$ to palladium nitrate does not accelerate the rate of TPB degradation over palladium nitrate alone. However, it can be seen that addition of diphenyl mercury does accelerate the reaction, and provides a decomposition rate comparable to that observed in the baseline reactions using palladium supported on alumina with diphenyl mercury. Reaction \#5, which contained only $\mathrm{PhHgNO} \cdot \mathrm{PhHgOH}$ and no palladium, showed no ingrowth of phenylborates (only TPB was present), indicating that no decomposition reaction had occurred. 


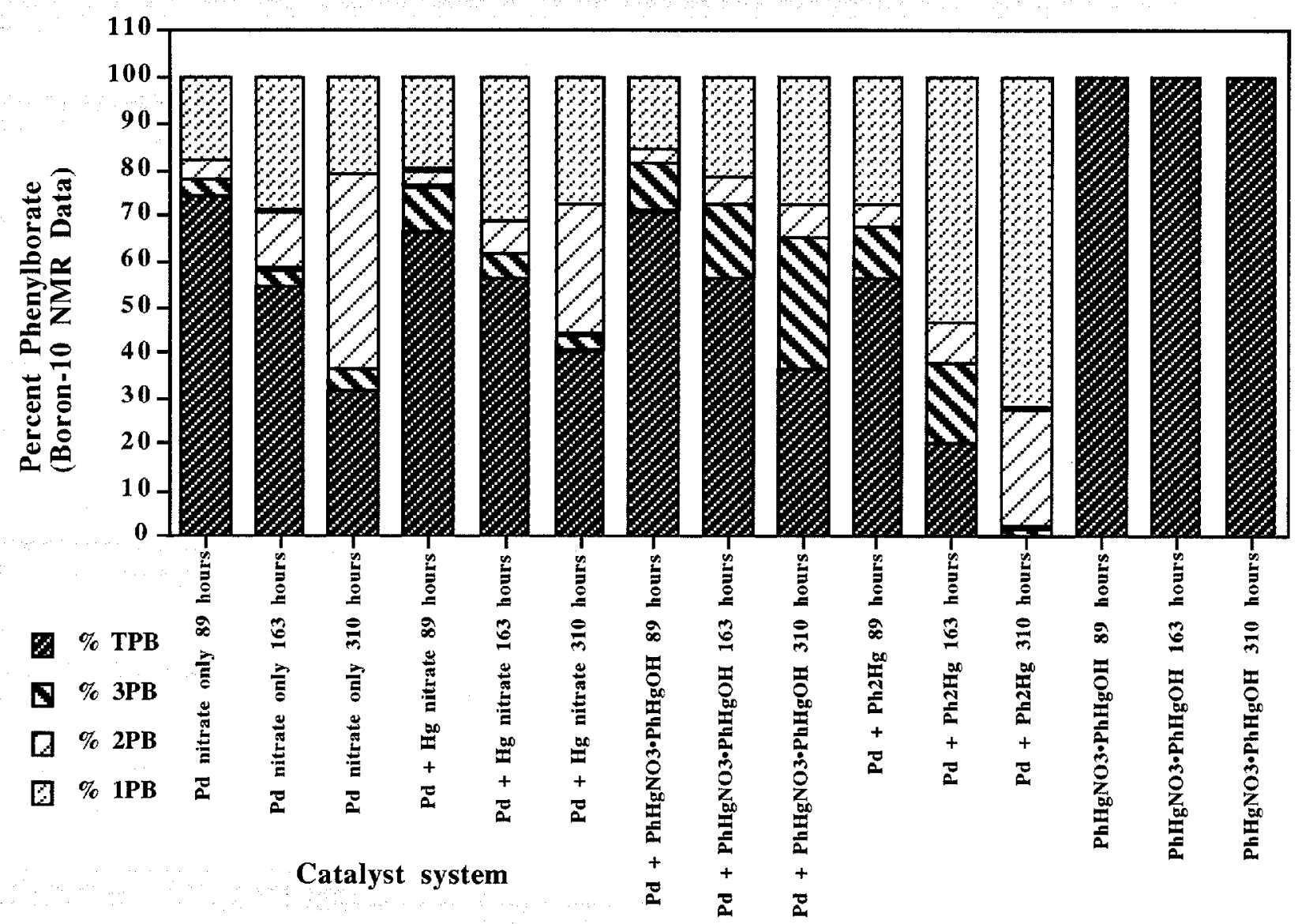

Figure 2. Distribution of phenylborates as a function of time at $45^{\circ} \mathrm{C}$ and catalyst type. 


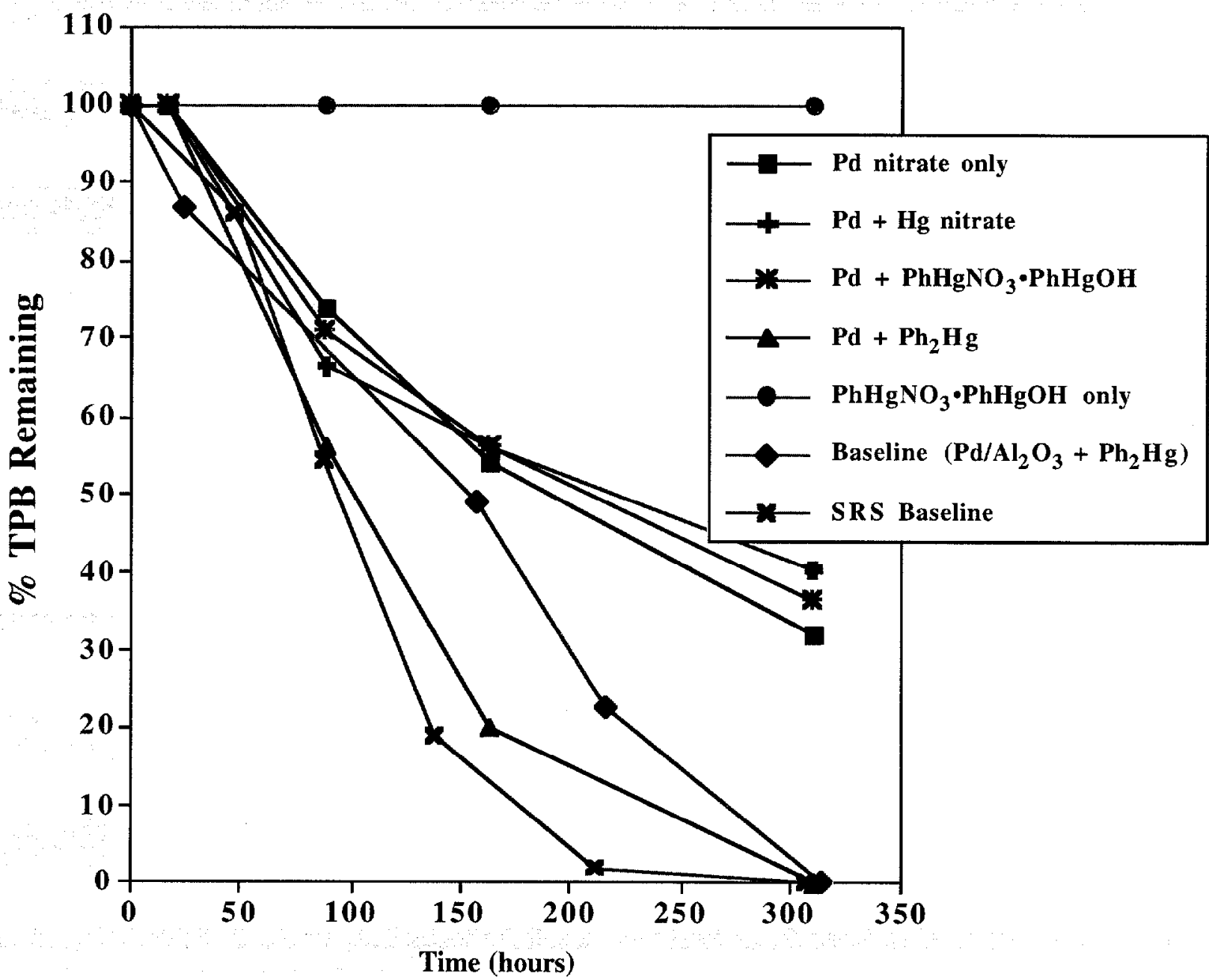

E

I

F

2

F

Figure 3. Rate of decomposition of TPB for five-catalyst experiment; baseline reactions from Figure 1 included for comparison. 
In Figures 4 through 7, the percentages of each phenylborate species (1PB, 2PB, 3PB, and TPB) are plotted for reaction bottle numbers $1-4$ as a function of time. A $\pm 5 \%$ can be assumed for the $\%$ phenylborate values. It can be seen that qualitatively speaking, the distribution of phenylborates during decomposition of TPB as a function of time is remarkably similar for the palladium nitrate only reaction (bottle \#1) and the palladium nitrate plus mercuric nitrate reaction (bottle \#2). In both cases the \% $2 \mathrm{~PB}$ is observed to grow in with time, whereas the \% 3PB remains low, and the $\% 1 \mathrm{~PB}$, after initially growing in, levels off. In contrast, reaction bottle \#3 (palladium nitrate plus $\mathrm{PhHgNO}_{3} \bullet \mathrm{PhHgOH}$ ), the \% 1PB and \% 3PB continue to grow in, while the $\% 2 \mathrm{~PB}$ remains at a low level. Reaction bottle \#4 (palladium nitrate plus diphenyl mercury) showed a rapid decrease in the \% TPB with a corresponding rapid increase in the $\% 1 \mathrm{~PB}$. The $\%$ $3 \mathrm{~PB}$ increases, then decreases, likely as it is decomposed to $1 \mathrm{~PB}$ and $2 \mathrm{~PB}$, the latter which slowly increases over the course of the reaction, so that at 310 hours only 1 PB and 2PB are observed.

The appearance of the solids and precipitates in the bottles was found to change over the course of the reaction. In particular, the precipitate in the Reaction bottle \#4 (palladium nitrate plus diphenyl mercury) changed from pale gray suspended colloids, some of which passed through the 0.45 micron filter to impart a grayish hue to the filtrate (at 17 and 89 hours), to a soot black precipitate that settled to the walls and bottom of the bottle, and which were completely retained on the filter such that the filtrate was clear and colorless (at 310 hours). At 163 hours, the appearance was midway between 89 and 310 hours, that is, there was some black precipitate, but still some grayish material passed through the filter to color the filtrate (though less so than at 89 hours). After 310 hours, the bottles were permanently removed from the $45^{\circ} \mathrm{C}$ oven, allowed to stand at room temperature overnight, then placed in a $4{ }^{\circ} \mathrm{C}$ refrigerator for temporary archival. After about 2 weeks in the refrigerator, the bottles were removed and allowed to come back to room temperature, and digital photographs were taken of the bottles using a ZoomCam USB for Mac digital camera, with still image capture resolution of 320 by 240 pixels. The images are shown in Figures 8-13. 


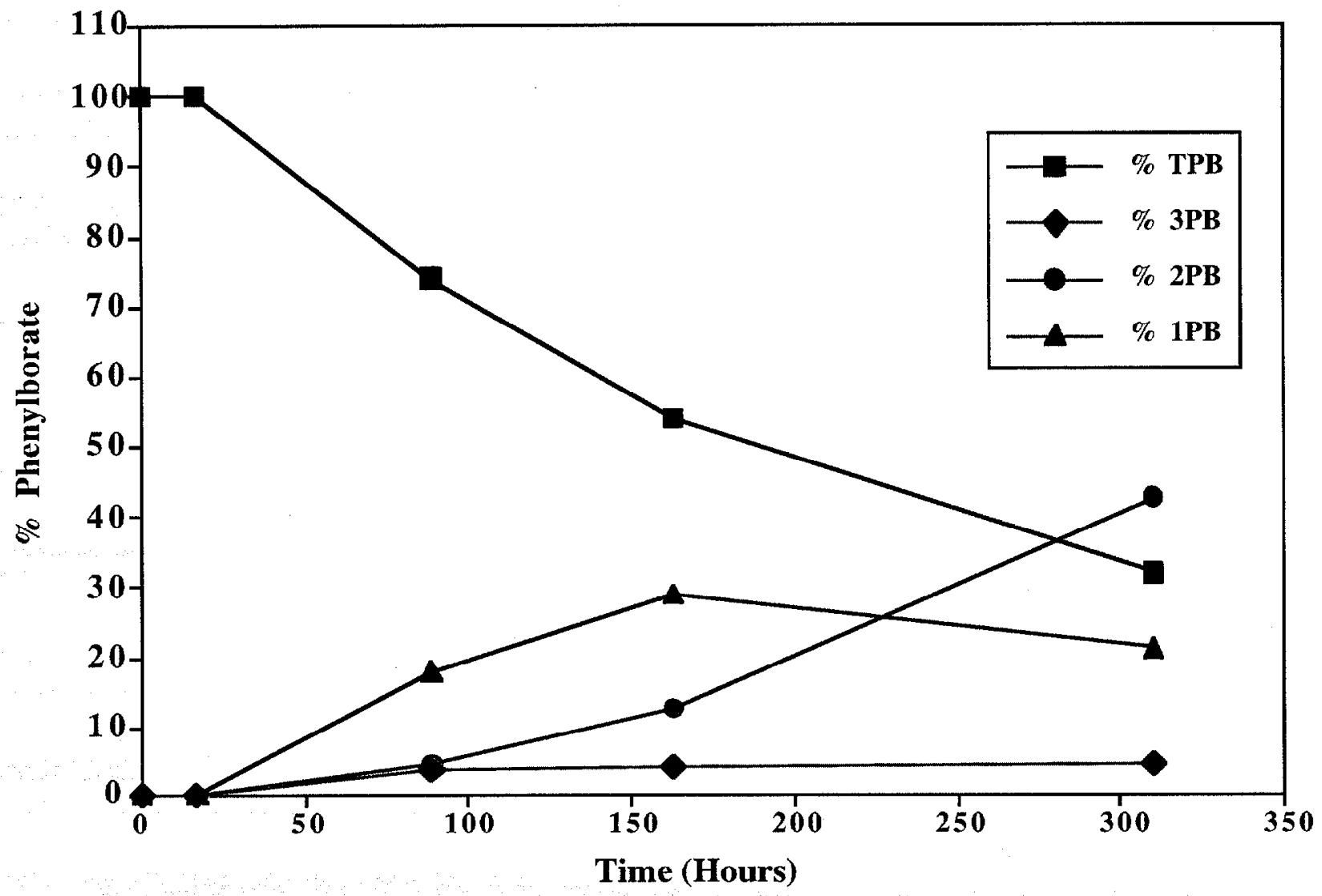

Figure 4. Distribution of phenylborates with time for Reaction \#1 (palladium nitrate only). 


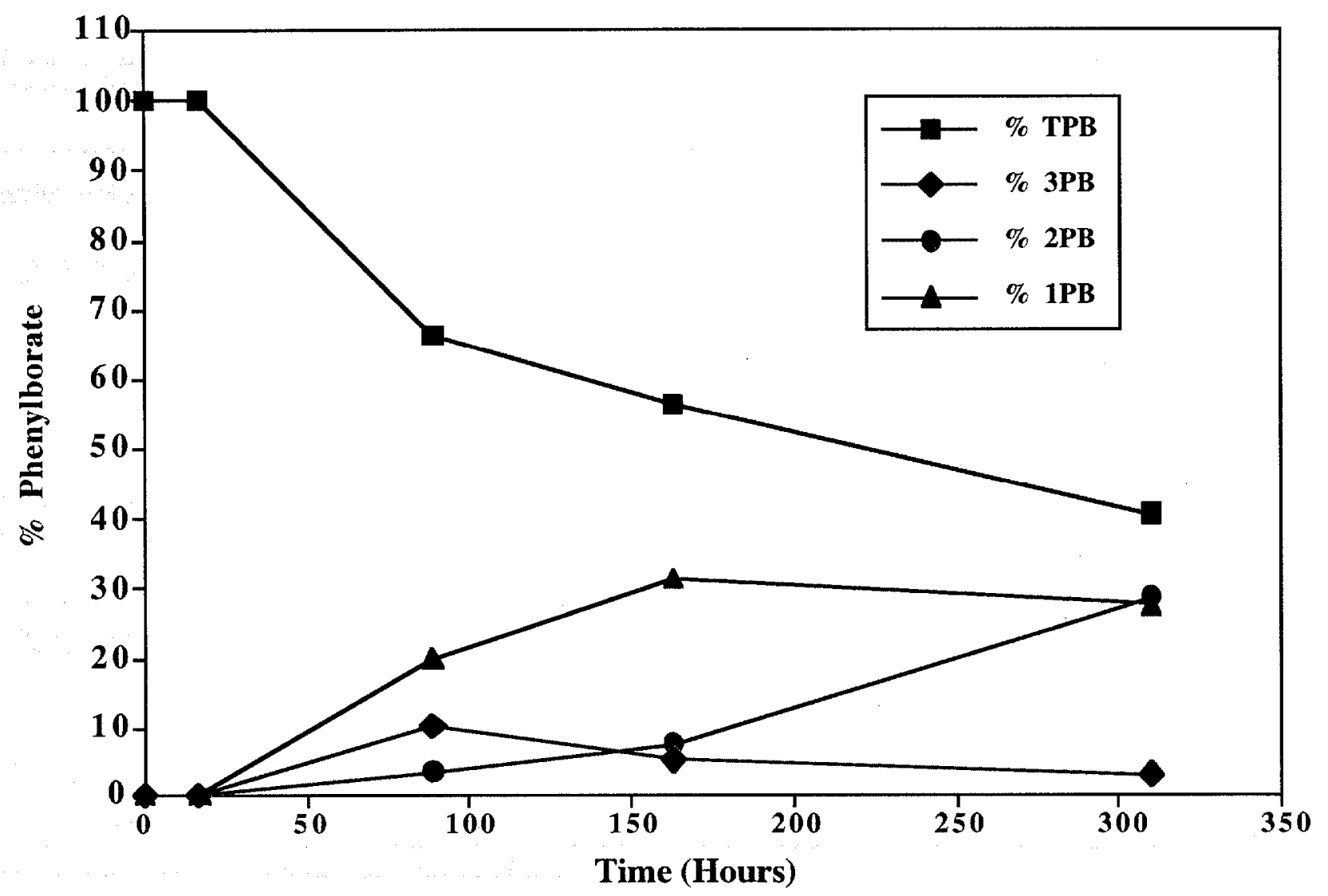

Figure 5. Distribution of phenylborates with time for Reaction \#2 (palladium nitrate plus mercuric nitrate). 


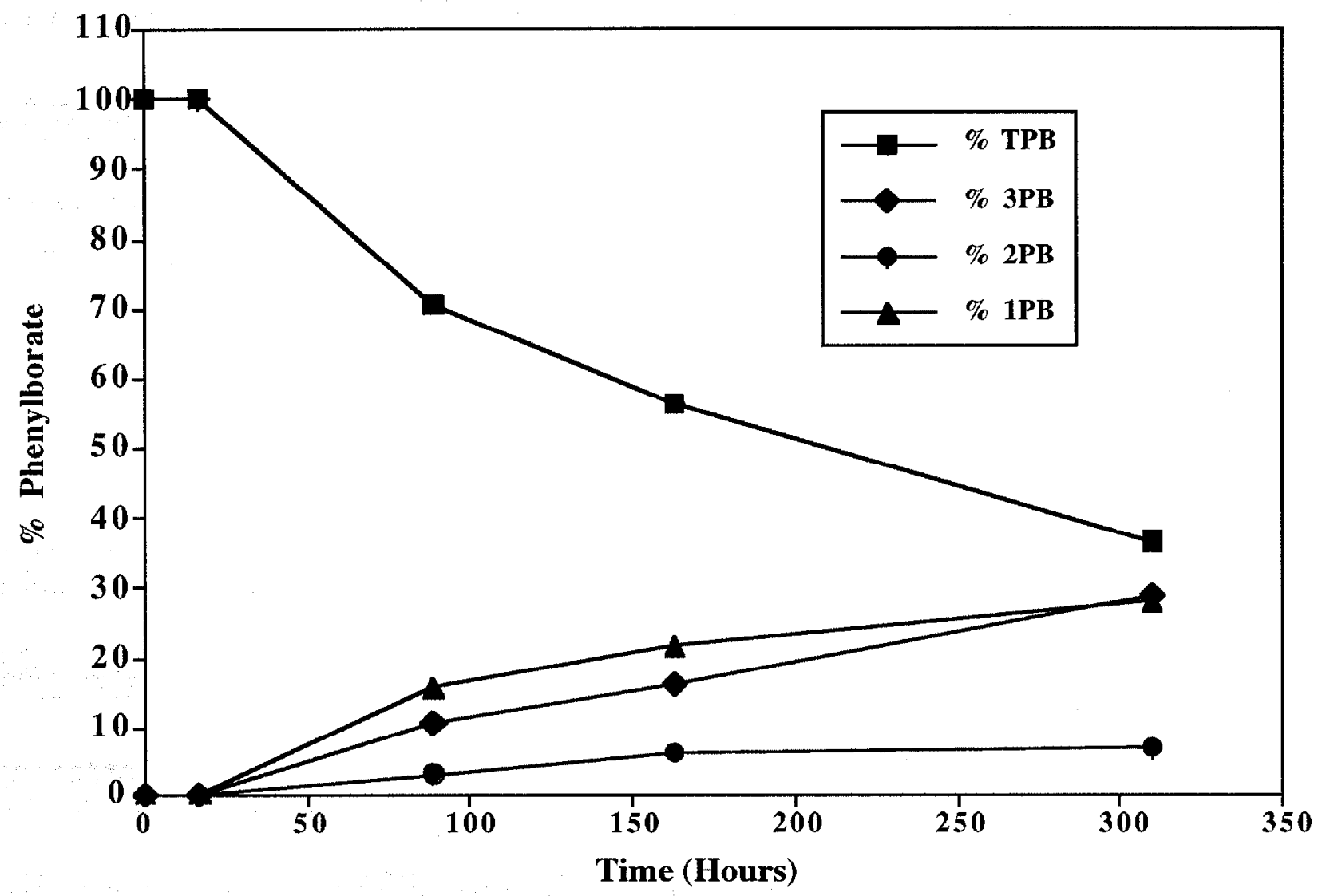

Figure 6. Distribution of phenylborates with time for Reaction \#3 (palladium nitrate plus $\mathrm{PhHgNO}_{3} \cdot \mathrm{PhHgOH}$ ). 


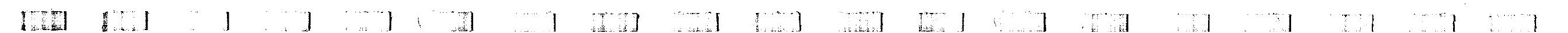




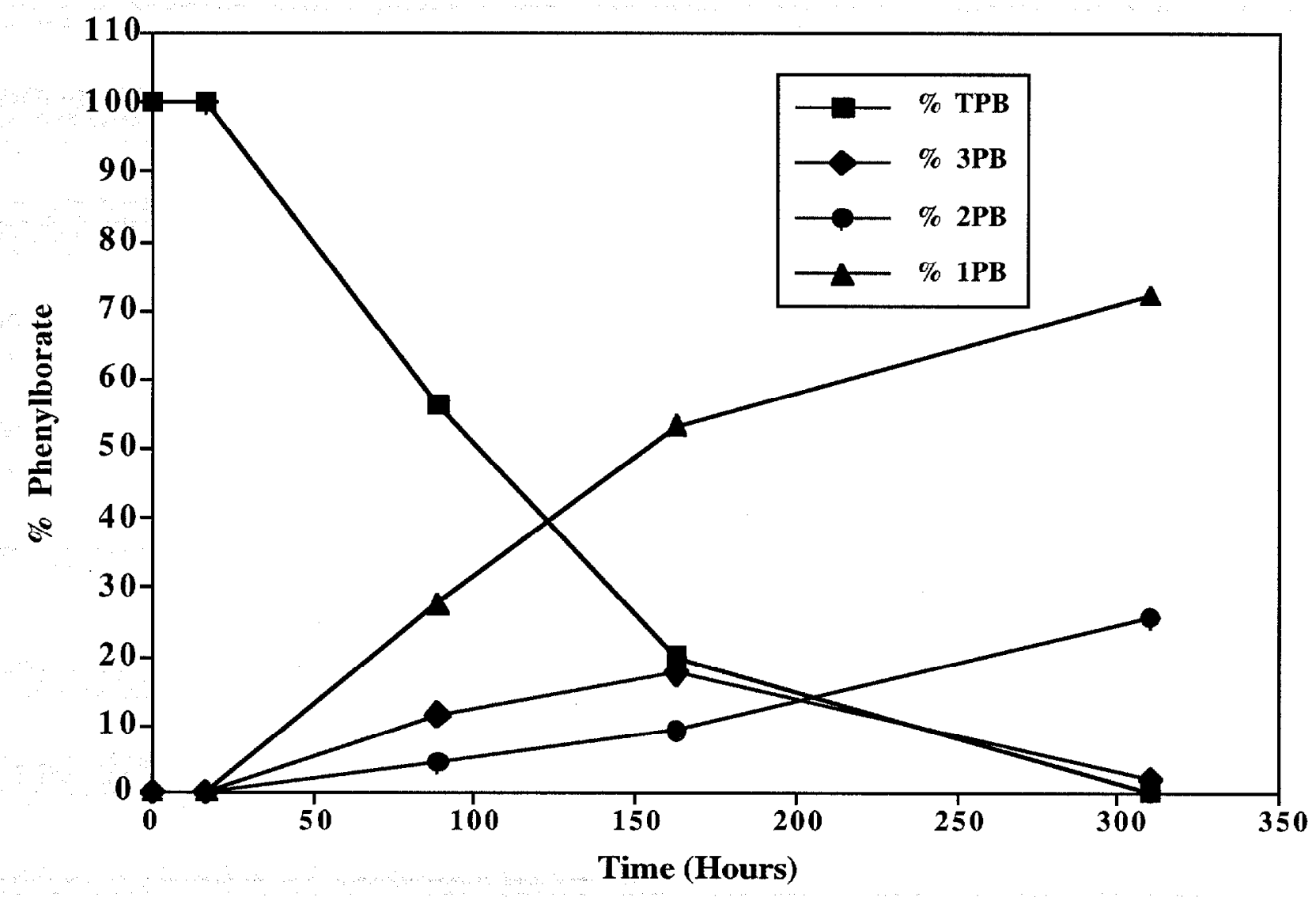

Figure 7. Distribution of phenylborates with time for Reaction \#4 (palladium nitrate plus diphenylmercury). 


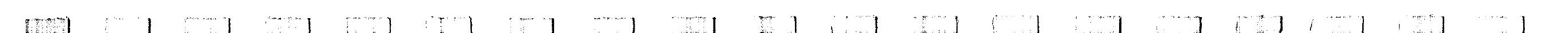




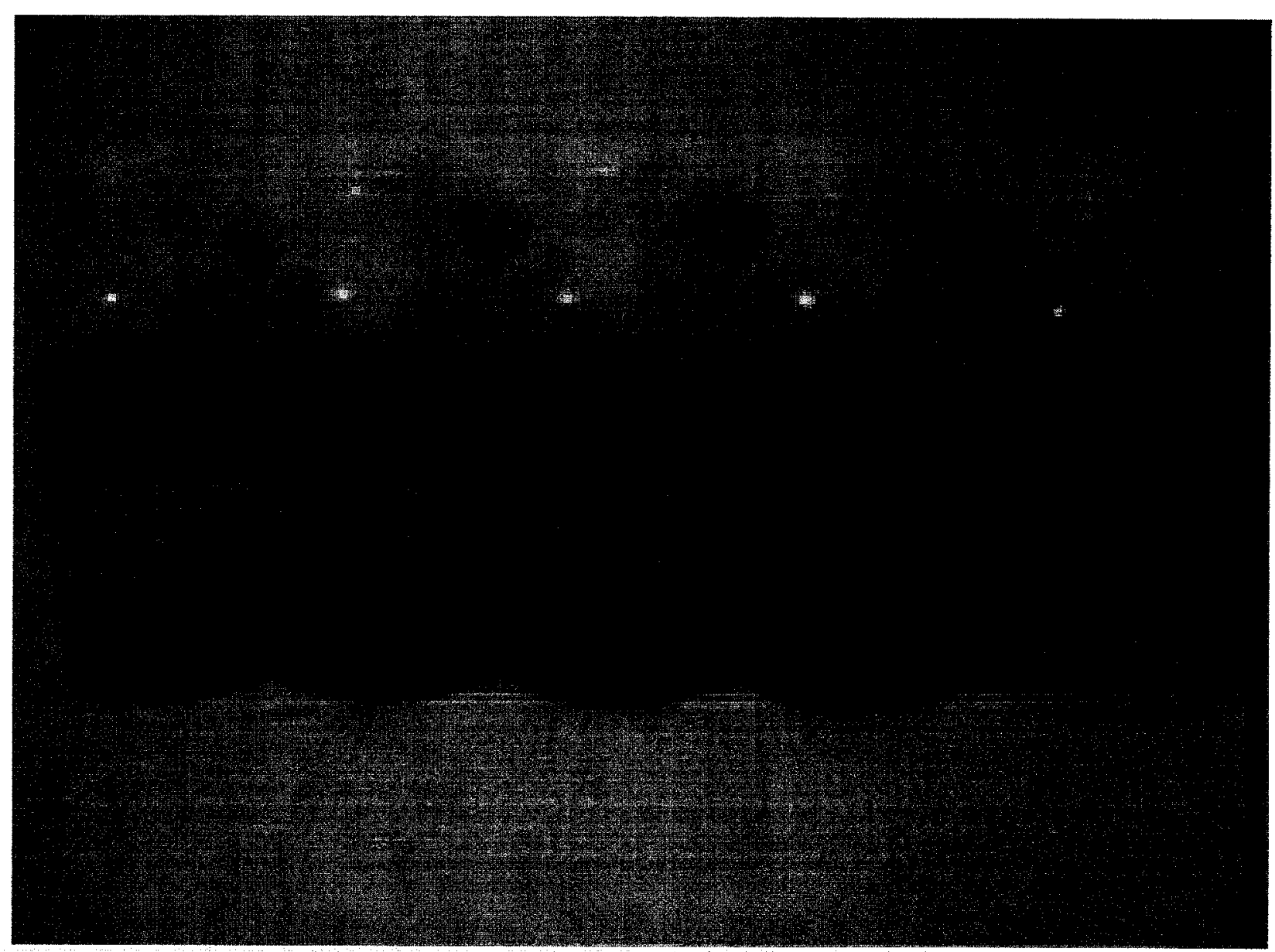

Figure 8. Appearance of all five reaction bottles after 310 hours and storage in a refrigerator. 


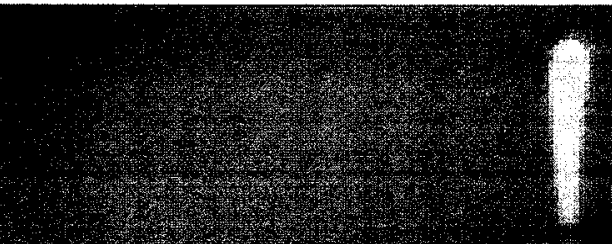

Figure 9. Appearance of bottle from Reaction \#1 (palladium nitrate only) after 310 hours and storage in a refrigerator. 
$-$ 

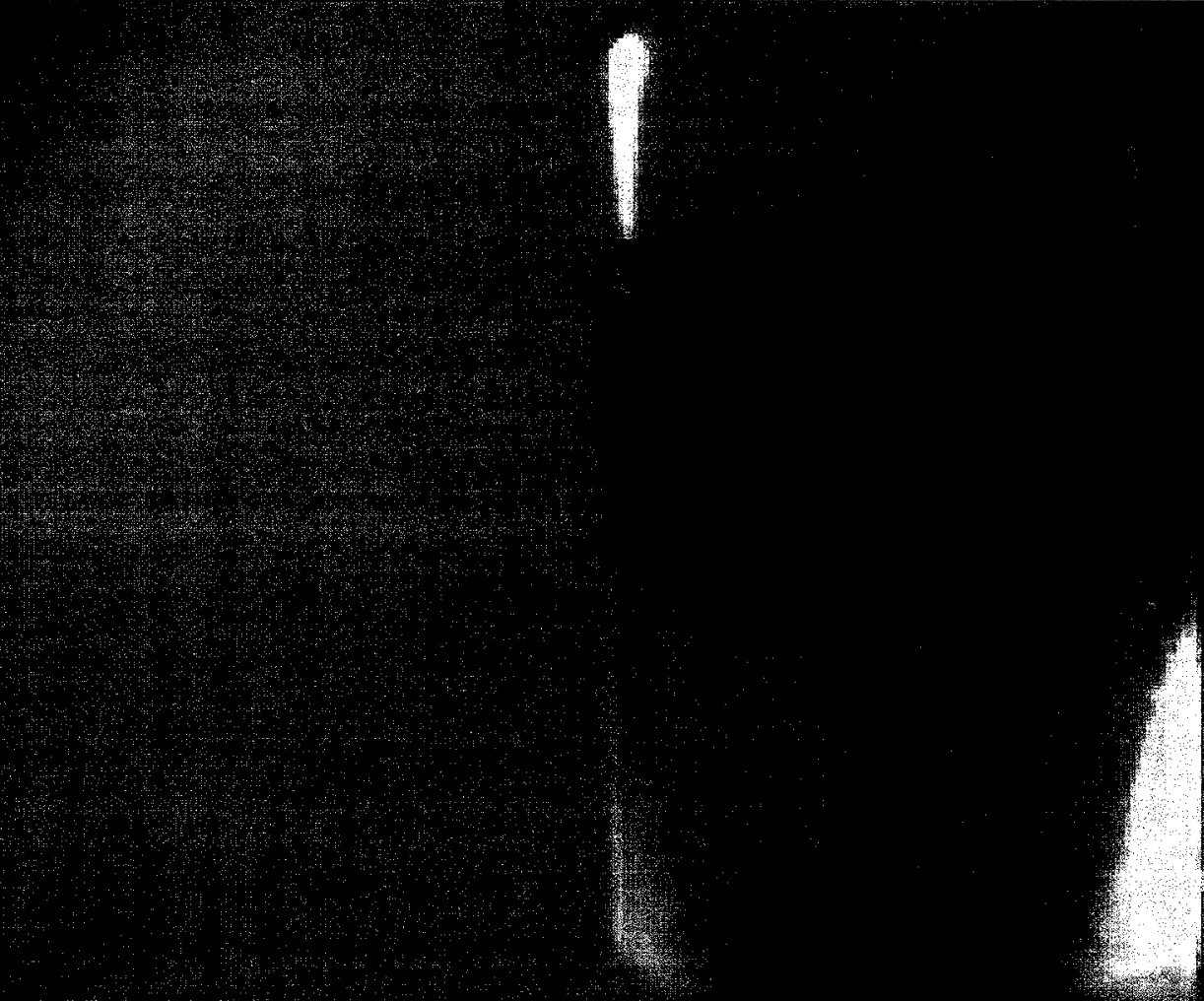

Figure 10. Appearance of bottle from Reaction \#2 (palladium nitrate plus mercuric nitrate) after 310 hours and storage in a refrigerator. 


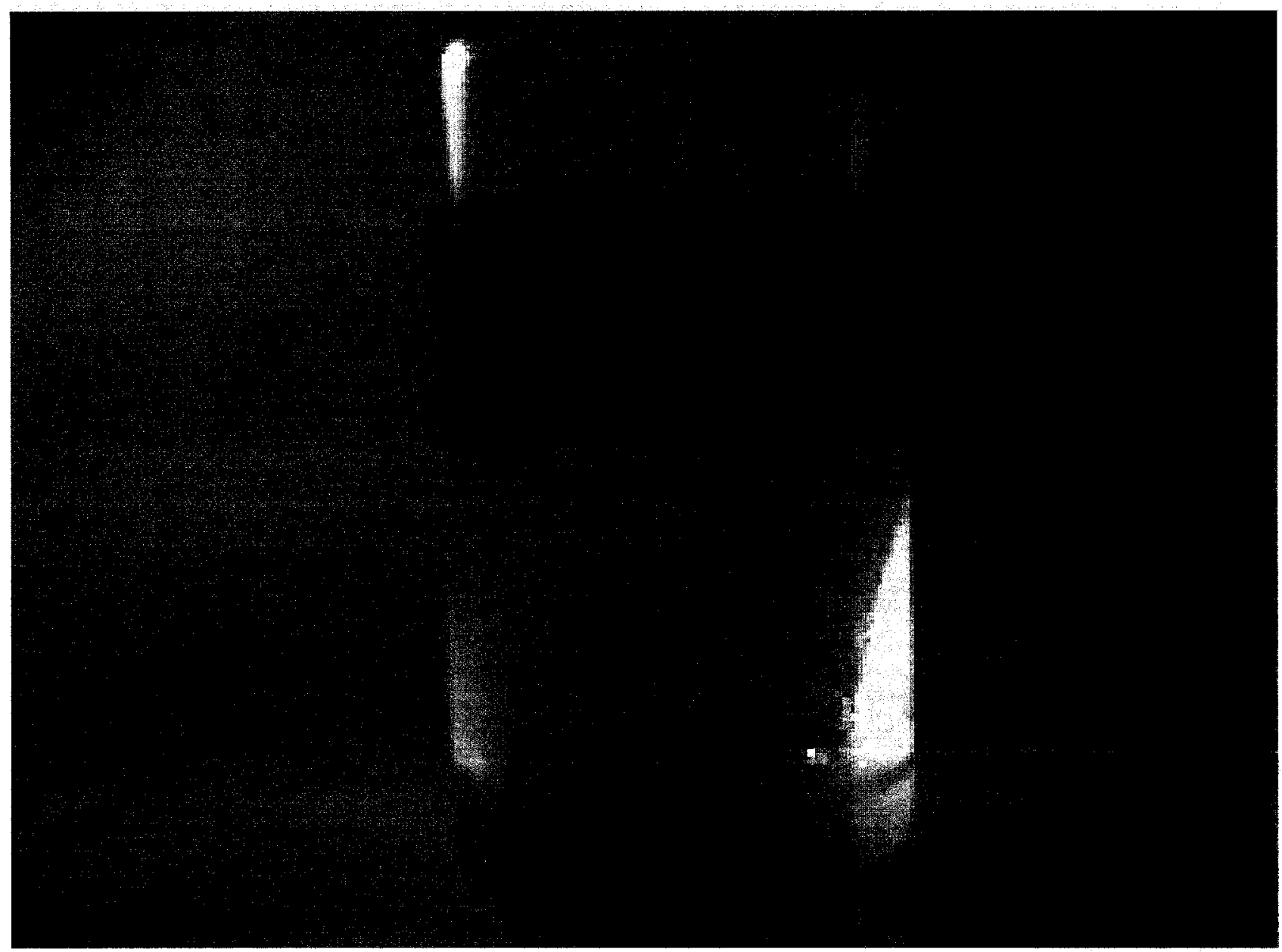

F

P

F

3

2

Figurc 11. Appcarance of bottle from Reaction \#3 (palladium nitrate plus 
Figure 12. Appearance of bottle from Reaction \#4 (palladium nitrate plus diphenylmercury) after 310 hours and storage in a refrigerator. 


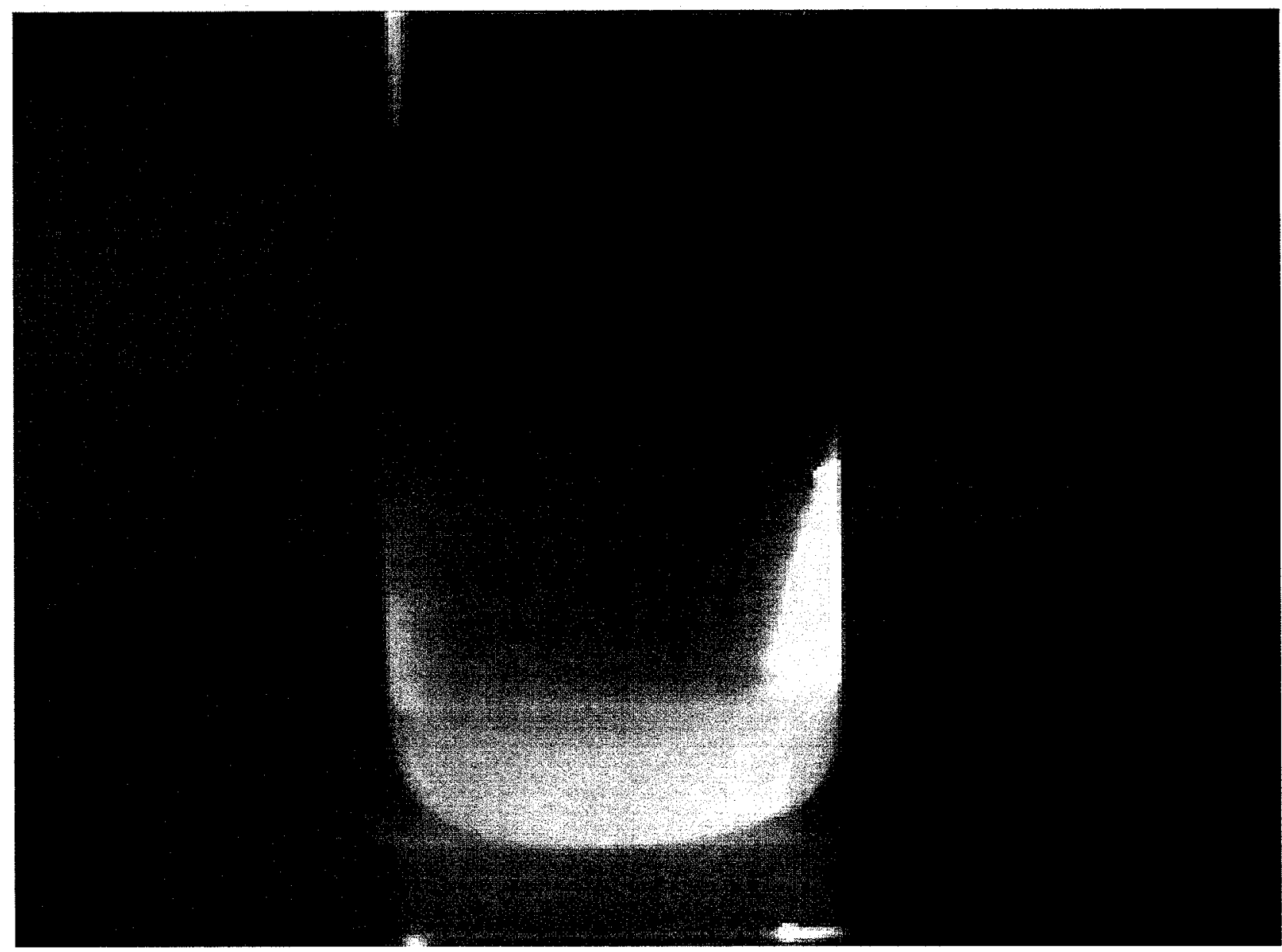

Figure 13. Appearance of bottle from Reaction \#5 (PhHgNO $\cdot \mathrm{PhHgOH}_{3}$ only) after $\mathbf{3 1 0}$ hours and storage in a refrigerator. 
Due to the low resolution of the images, it is difficult to distinguish differences in the nature of the solids in bottle numbers $1-3$, however the difference in the appearance of bottle \#4 can still be discerned.

\subsection{CONCLUSIONS AND FUTURE PLANS}

The key findings from this study can be summarized as follows: 1) palladium appears to be capable of catalyzing the degradation in the absence of mercury; 2) when mercury was added to the palladium system in the form of mercuric nitrate or phenylmercuric nitrate basic, the rate of TPB degradation was roughly the same as the rate without mercury present; 3) when mercury was added to the system in the form of diphenylmercury, the rate of TPB degradation was greatly accelerated; 4) no TPB degradation was observed for a system which contained phenylmercuric nitrate basic alone with no palladium present; 5 ) the distribution of lower phenylborates (1PB, $2 \mathrm{~PB}$, and $3 \mathrm{~PB}$ ) varied as a function of the catalyst system; 6) no lower phenylborates were observed during the first 17 hours of reaction indicating that an "induction period" may be necessary; and 7) the appearance of precipitates in the reaction mixture varied with the catalyst system, possibly indicating that the active catalyst that is formed may vary with the chemical form of mercury added.

With regard to the first finding, it is known that under basic conditions palladium can catalyze cross-coupling reactions between aryl halides and aryl boronic acids (the Suzuki reaction) [12]. With regard to finding number 5 , it is also known that $\mathrm{HgX}_{2}$ and $\mathrm{RHgX}$ salts do react with NaTPB to form 3PB and $\mathrm{Ph}_{2} \mathrm{Hg}$ and $\mathrm{RPhHg}$, respectively [Boncella handout in ref 12]. However, since the TPB is 100 times the concentration of $\mathrm{PhHgNO}_{3} \cdot \mathrm{PhHgOH}$, it is quite likely that there was an initial reaction of $1 \%$ of the NaTPB with the $\mathrm{PhHgNO}_{3} \cdot \mathrm{PhHgOH}$ to form insoluble $\mathrm{Ph}_{2} \mathrm{Hg}$, which, without the palladium present, may be unable to catalytically degrade TPB (this point needs to be further investigated by using $\mathrm{Ph}_{2} \mathrm{Hg}$ alone). In the Boron-10 NMR, there was perhaps a trace of lower phenylborates in bottle \#5 reaction, but the signal-to-noise ratio was too small to obtain a quantitative measurement. With regard to findings two and three, it is not entirely clear why the reaction was accelerated with $\mathrm{Ph}_{2} \mathrm{Hg}$ but not with mercuric nitrate or $\mathrm{PhHgNO}_{3} \cdot \mathrm{PhHgOH}$. One possibility is that in the form of mercuric nitrate or $\mathrm{PhHgNO}_{3} \cdot \mathrm{PhHgOH}$, there is no "synergism" between the palladium and the mercury. Palladium independently catalyzes TPB degradation perhaps by the Suzuki-type reaction observed in reaction $\# 1$, and the mercury compounds independently react stoichiometrically with NaTPB to form $3 \mathrm{~PB}$, perhaps in the same manner as in reaction \#5. However, such stoichiometric reactions should convert the mercury compounds to $\mathrm{Ph}_{2} \mathrm{Hg}$, thus generating in situ the chemical reagent conditions 
of reaction \#4 (palladium with $\mathrm{Ph}_{2} \mathrm{Hg}$ ). One possible explanation for these seemingly conflicting results is that when palladium nitrate and $\mathrm{Ph}_{2} \mathrm{Hg}$ are present at the start of the reaction, some interaction between them, possibly involving TPB or another phenylborate, occurs, to form an active catalyst containing both mercury and palladium. However in the situation where $\mathrm{Ph}_{2} \mathrm{Hg}$ is slowly generated in situ, the palladium may be in a form (as it is catalyzing the Suzuki reaction) that doesn't interact with $\mathrm{Ph}_{2} \mathrm{Hg}$ in a manner to generate the most active catalyst system. This is speculation, and the inconsistency needs to be further explored. A way to test this could be to repeat reaction \#1, and then add $\mathrm{Ph}_{2} \mathrm{Hg}$ part way through the ongoing reaction (e.g., after say 72 hours) to see if the reaction rate accelerates. Findings six and seven suggest that there is some interaction between palladium and $\mathrm{Ph}_{2} \mathrm{Hg}$ that takes time, and that the active catalytic species may require certain conditions to form. The species formed from palladium and $\mathrm{Ph}_{2} \mathrm{Hg}$ when added together is somehow different from the species formed when $\mathrm{Ph}_{2} \mathrm{Hg}$ is generated in situ while palladium is already engaged in a catalytic reaction. 


\subsection{REFERENCES}

[1] Walker, D. D.; Barnes, M. J.; Crawford, C. L.; Peterson, R. A.; Swingle, R. F.; and Fink, S. D. In Science and Technology for Disposal of Radioactive Tank Wastes; Schulz, W. W., Lombardo, N. J., Eds., Plenum, New York, NY, 1998; pp. 219-230.

[2] Walker, D.D. "Effect of Palladium Form on Tetraphenylborale Decomposition Rate", Westinghouse Savannah River Company Report No. WSRC-TR-98-00073, Rev. 0, April, 1998, and references cited.

[3] Dixon, D. A.; Isern, N. G.; Ellis, P. D.; Bowman, M. K. "Research on Decomposition of Tetraphenylborate for ITP at SRS"; EMSL Report, Pacific Northwest National Laboratory: Richland, WA, 1997.

[4] Brevard; C.; Granger; P. Handbook of High Resolution Multinuclear NMR; John Wiley \& Sons, Inc.: New York, 1981, pp. 160-161; 204-205.

[5] Wittig, V.G. Raff, P. Justus Liebigs Ann. Chem. 1950, 573, 195-209.

[6] Wakefield, B. J. Organomagnesium Methods in Organic Synthesis, Academic Press: New York, 1995.

[7] Pavia, D.L.; Lampman, G. M.; Kriz, G.S., Jr. Introduction to Organic Laboratory Techniques: A Contemporary Approach, $2^{\text {nd }}$ Edition, W.B. Saunders Co: Philadelphia, 1982; pp. 222-228.

[8] Nishida, H.; Takada, N.; Yoshimura, M.; Sonada, T.; Kobayashi, H. Bull. Chem. Soc. Jpn. 1984, 57, 2600-2604.

[9] Holzapfel, H.; Richter, C. J. Prakt. Chem. 1964, 26, 15-23.

[10] Williams, J.L.R.; Doty, J.C.; Grisdale, P. J.; Searle, R.; Regan, T. H.; Happ, G. P.; Maier, D. P. J. Amer. Chem. Soc. 1967, 89, 5153-5157. 
[11] (a) Barnes, M. J.; Fink, S. D., Eds. "Summary Report of the Small Tank Tetraphenylborate Catalyst Consultant Meeting, May 10, 2000", Westinghouse Savannah River Company Report No. SRT-LWP-2000-00117, July, 2000. (b) Peterson, R. A.; Barnes, M. J. "Results of Experimental Investigation into Noble Metal Catalyzed Decomposition of Sodium Tetraphenylborate", Westinghouse Savannah River Company Report No. WSRC-TR-2000-00.

[12] Boncella, J. M. "Literature Review on Tetraphenyl Borate Hydrolysis Processes", in Barnes, M. J.; Fink, S. D., Eds. "Summary Report of the Small Tank Tetraphenylborate Catalyst Consultant Meeting, May 10, 2000", Westinghouse Savannah River Company Report No. SRT-LWP-2000-00117, July, 2000. 
ORNL/-TM-2000/279

\section{INTERNAL DISTRIBUTION}

1-3. P. V. Bonnesen (3 copies)

4. D. A. Bostick

5. J. L. Collins

6. L. H. Delmau

7. R. D. Hunt

8. R. T. Jubin

9. T. E. Kent

10. D. D. Lee

11. C. P. McGinnis
12. L. E. McNeese

13. F. V. Sloop, Jr.

14. P. A. Taylor

15-17. J. F. Walker (3 copies)

18. ORNL Central Research Library

19. Laboratory Records, RC

20. Laboratory Records, OSTI

\section{EXTERNAL DISTRIBUTION}

21. M. J. Barnes, Westinghouse Savannah River Company, P.O. Box 616, 773-A, Room B1 12, Aiken, SC 29808

22. Boncella, J. M., Dept. of Chemistry and Center for Catalysis, University of Florida, Gainesville, FL. 32611-7200

23. J. T. Carter, Westinghouse Savannah River Company, P.O. Box 616, 704-3N, Room S151, Aiken, SC 29808

24. M. C. Duff, Savannah River Ecology Laboratory, c/o 737-A, Aiken, SC 29808

25. Herbert H. Elder, Westinghouse Savannah River Company, P.O. Box 616, 704-3N, Room S151, Aiken, SC 29808

26. Samuel D. Fink, Westinghouse Savannah River Company, P.O. Box 616, 773-A, Room B1 12, Aiken, SC 29808

27. Roger L Gilchrist, Pacific Northwest National Laboratory, P.O. Box 999, MS:K9-91, Richland, WA 99352

28. T. S. Gutmann, U.S. Department of Energy, Savannah River Operations Office, P.O. Box A, Aiken, SC 29802

29. H. D. Harmon, Tank Focus Area Salt Processing Program, P.O. Box 616, 704-3N, Room S151, Aiken, SC 29808

30. J. O. Honeyman, Lockheed Martin Hanford Corporation, P.O. Box 1500, MS: G3-21, Richland, WA 99352

31. Jim Jewett, Numatec Hanford Corporation, P.O. Box 1970, Richland, WA 99352

32. R. T. Jones, Westinghouse Savannah River Company, P.O. Box 616, 704-3N, Room S122, Aiken, SC 29808.

33. R. B. King, Dept. of Chemistry, University of Georgia, Athens, Georgia 30602-2556 
34. R. A. Kirkbride, Numatec Hanford Corporation, P.O. Box 1970, MS: H5-27, Richland, WA 99352

35. C. S. Louie, U.S. Department of Energy, Richland Operations Office, P.O. Box 550, MSIN: B4-55, Richland, WA 99352

36. C. L. Leung, Westinghouse Savannah River Company, P.O. Box 616, 704-3N, Room S151, Aiken, SC 29808

37. J. P. Morin, Westinghouse Savannah River Company, P.O. Box 616, Savannah River Technology Center, 703-H, Aiken, SC 29808

38. Lynn Nelson, Westinghouse Savannah River Company, P.O. Box 616, 773-A, Room-B-112, Aiken, SC 29808

39. J. R. Noble-Dial, U.S. Department of Energy, Oak Ridge Operations Office, P.O. Box 2001, Oak Ridge, TN 37831-8620

40. L. M. Papouchado, Westinghouse Savannah River Company, P.O. Box 616, 773-A, Room A-263, Aiken, SC 29808

41. R. A. Peterson, Westinghouse Savannah River Company, P.O. Box 616, 773-A, Room B-132, Aiken, SC 29808

42. S. F. Piccolo, Westinghouse Savannah River Company, P.O. Box 616, 704-3N, Room S152, Aiken, SC 29808

43. J. M. Reynolds II, U.S. Department of Energy, Savannah River Operations Office, P.O. Box A, Building 704-196N, Room S441, Aiken, SC 29802

44. K. J. Rueter, Westinghouse Savannah River Company, P.O. Box 616, 706-S, Room 103, Aiken, SC 29808

45. W. W. Schulz, 12704 Sandia Ridge Place NE, Albuquerque, NM 87111

46. Patricia C Suggs, US Department of Energy, Savannah River Operations Office, P.O. Box A, Building 704-196N, Room S431, Aiken, SC 29802

47. S. N. Schlahta, Tank Focus Area Salt Processing Program, P.O. Box 616, 704-3N, Room S151, Aiken, SC 29808

48. J. L. Swanson, 1318 Cottonwood, Richland, WA 99352

49. W. L. Tamosaitis, Westinghouse Savannah River Company, P.O. Box 616, 773-A, Room A-231, Aiken, SC 29808

50. Larry Tavlarides, Syracus University, Dept. of Chemical Engineering \& Materials Science, 334 Hinds Hall, Syracuse, NY 13244-1190

51. T. A. Todd, Idaho National Engineering and Environmental Laboratory, Building 637, MS-5218, Idaho Falls, ID 83415-5218

52. George Vandegrift, Argonne National Laboratory, Building 205, 9700 South Cass Avenue, Argonne, IL 60439 
53. J. H. Westsik, Pacific Northwest National Laboratory, P.O. Box 999, MS:K9-91, Richland, WA 99352

54. W. R. Wilmarth, Westinghouse Savannah River Company, P.O. Box 616, 773-42A, Room 153, Aiken, SC 29808

55. P. E. Woodall, U.S. Department of Energy, Idaho Operations Office, 750 DOE Place (MS 1145), Idaho Falls, ID 83402

56-61. Tanks Focus Area Technical Team, c/o B. J. Williams, Pacific Northwest National Laboratory, P.O. Box 999, MSIN K9-69, Richland, WA 99352

62. Tanks Focus Area Field Lead, c/o T. P. Pietrok, US Department of Energy, Richland Operations Office, P.O. Box 550, MS: K8-50, Richland, WA 99352 
